\title{
The influence of chain defects on the crystallisation behaviour of isotactic polypropylene
}

\author{
D. W. van der Meer ${ }^{1,2}, J_{\text {Varga }}{ }^{*}$, G. J. Vancso ${ }^{1}$ \\ ${ }^{1}$ Department of Materials Science and Technology of Polymers and MESA+ Research Institute for Nanotechnology, \\ University of Twente, P.O.Box 217, 7500 AE Enschede, The Netherlands \\ ${ }^{2}$ Dutch Polymer Institute, P.O.Box 217, 7500 AE Enschede, The Netherlands \\ ${ }^{3}$ Department of Physical Chemistry and Materials Science, Laboratory of Plastics and Rubber Technology, Budapest \\ University of Technology and Economics, H-1111 Budapest, Müegyetem rkp. 3., Hungary
}

\begin{abstract}
The crystallization characteristics of the $\alpha$-, $\beta$-and $\gamma$-phases of isotactic polypropylene were studied for welldefined and fully characterized polymers with varying amounts of stereo- and regio-defects. The specimens enabled us to study separately the influence of the type of chain defect and the concentration of defects on the parameters of interest. A combined defect fraction (CDF) was introduced to describe arbitrary iPP samples with a varying amount of stereo- and regio-defects and a combination thereof. Crystal growth rates were found to decrease linearly with the defect fraction and were substantially stronger influenced by regio-defects as compared with stereo-defects. The deceleration of the growth rate of the $\beta$-phase is higher compared to the $\alpha$-phase with increasing defect fraction. We also found a critical defect fraction, $\left(X_{\text {crit }}\right)$ for which the growth rates of the $\alpha$ - and $\beta$-phases are equal. Analysis of the crystallization was performed using the model of Sanchez and Eby. Results of the analysis are in good agreement with the results found for the samples with a variation in the number of stereo-defects. The excess free energy for incorporating a stereo-defect into the trigonal crystal lattice of the $\beta$-phase is lower as compared with the $\alpha$-phase. The theory correctly predicts the critical defect fraction, for which the growth rate of the $\alpha$ - and $\beta$-phase is equal.
\end{abstract}

Keywords: polymer blends and alloys, isotactic polypropylene, beta-nucleation, stereo- and regio-defects, thermal properties

\section{Introduction}

The various forms of the crystalline morphology of polymers can be directly derived from the mechanisms and kinetics of crystallization, which - in turn - depend on the primary chemical structure and chain topology of macromolecules [1]. Therefore, it is of great importance to understand the influence of the primary structure on the different aspects of crystallization and on the resulting morphology. Variations in the morphology due to incorporation of defects in the chain take place on the secondary and higher levels of the morphological hierarchy, i.e. on the lamellar level and on the spherulitic level
$[2,3]$. Several studies addressed the effects of chain architecture on the various levels of the morphology and crystallization behaviour of isotactic polypropylene (iPP) [2-5]. Yet as the availability of PP chains with well-defined primary structure has been limited, no seminal conclusions regarding morphologystructure behaviour have been reached.

In iPP, which exhibits polymorphism, the relative amounts of the different crystal phases $(\alpha, \beta$, and $\gamma)$ may change as function of chain regularity. Especially in metallocene catalysed polymers, an enhancement in the formation of the $\gamma$-phase can be seen [4, 6]. This was ascribed to a decrease in crystallisable

\footnotetext{
${ }^{*}$ Corresponding author, e-mail: Jvarga@mail.bme.hu

(C) BME-PT
} 
sequence length as a consequence of an increase in the fraction stereo- and regio-defects [7], or morphological effects that render the chain folding in lamellae more difficult [8]. Morphology changes on the spherulitic level for iPP involve variations in the crosshatched structure of the $\alpha$-phase and the frequency of branching in the $\beta$-phase [5, 9]. Naturally, changes in the morphology on the spherulitic level take place due to variations in the relative amounts of the $\beta$ - and $\gamma$-phases compared to the commonly existing $\alpha$-phase.

The influence of chain architecture on the crystallization behaviour of the $\beta$-phase has not been extensively studied; certainly not at the extent as it has been performed for the $\alpha$-phase. We have been particularly interested in the $\beta$-phase as this structure has better impact properties than the typical $\alpha$-phase [10, 11]. Thus the influence of one property shortcoming of PP, i.e. mediocre toughness, can in principle be improved by increasing the amount of the $\beta$-polymorph. Varga and Schulek-Tóth [12] found that the formation of the $\beta$-phase was strongly restricted in copolymers of propylene and ethylene. Growth rates of the $\beta$-phase in these copolymers were found to be lower for all temperatures studied [13] as compared to pure homopolymers. In these studies selective nucleating agents were used to induce the nucleation of the $\beta$-phase. Formation of the $\beta$-phase can also be enhanced by shearing the melt prior to crystallization. Shear stress generated for example by pulling a fibre through an undercooled melt produces row nuclei consisting of the $\alpha$-phase, inducing the growth of a cylindrical growth front consisting of the $\beta$-phase. Several studies [14-19] were dealing with parameters that influence the formation of such $\beta$-cylindrites, like the temperature of pulling $\left(T_{\text {pull }}\right)$, crystallization temperature $\left(T_{\mathrm{c}}\right)$, time of pulling $\left(t_{\text {pull }}\right)$, speed of fibre pull $\left(v_{\text {pull }}\right)$, etc. The conclusion from these studies was that samples rich in $\beta$-phase are formed when $T_{\alpha \beta}<T_{\mathrm{c}} \leq T_{\text {pull }}<T_{\beta \alpha}$, where $T_{\alpha \beta}$ and $T_{\beta \alpha}$ are the lower and upper critical crystallisation temperatures for the formation of the $\beta$-phase, respectively [19]. As described in reference [20], a lowering of the upper critical temperature $\left(T_{\beta \alpha}\right)$ due to the presence of chain defects is predicted. In this study we will investigate the influence of chain defects on $T_{\beta \alpha}$ and on the formation of $\beta$-cylindrites.

In order to perform rigorous analyses of (chain) structure-property relationships, well defined and well characterized samples are needed. Most of the aforementioned studies lack a complete characterization of the chain microstructure of the polymer specimen used and the studies are usually restricted to providing the percentage $m$-pentads $(\%[\mathrm{mmmm}]$ ). Moreover, in most cases the polymers used were polypropylenes produced with Ziegler-Natta $(\mathrm{ZN})$ catalysts. As polymers obtained by ZN stereospecific polymerizations exhibit heterogeneous chemical and stereo-chemical distributions within one batch and within a single polymer chain, these macromolecules are not very well suitable for structure-property studies.

With the advent and widespread availability of iPPs obtained by metallocene polymerizations (m-iPPs) it is now possible to perform rigorous scientific chain architecture - polymer morphology studies. Metallocene catalysts are essentially composed of a single type of catalytic active centres, which produce rather uniform homo- and copolymers. Structural uniformity in these polymers is far superior compared with ZN catalysed chains [5, 21]. Possible defects are distributed homogeneously in the chain and all chains possess a practically equal number and distribution of defects [21]. In addition to the conventional ZN catalysed iPPs, which contain only stereo-defects, metallocene catalysed iPPs include also regiodefects. Furthermore, the length (molar mass) distribution of polymers obtained by metallocene catalysis is much narrower as compared with ZN catalysed polymers.

In this study we collected a number of iPPs obtained by metallocene catalysis from different manufacturers, made by using various catalysts. The samples were fully characterized by ${ }^{13} \mathrm{C}$ nuclear magnetic resonance $\left({ }^{13} \mathrm{C}\right.$-NMR). In this study two distinguishable groups of polymer samples are used. The first group exhibits a variation in the number of regiodefects, however with a constant amount of stereodefects. The second group possesses a varying amount of stereo-defects but virtually no regiodefects. Especially the latter group is interesting, as these m-iPPs without regio-defects are not widely available. This collection of polymers provides us with the possibility to investigate independently the influence of regio- and stereo-defects on the crystallization behaviour and morphology of iPP. Such comprehensive and comparative studies, to our knowledge, have not been presented. 
In the present paper we discuss the crystallization behaviour of the $\alpha-, \beta$-, and $\gamma$-phases as a function of stereo- and regio-defects in the polymer chain. An elaborate description of the samples used is given. Spherulitic growth rates are measured for the different polymorphs of iPP by a combined use of polarised light microscopy (PLM) and hot-stage (thermooptical method). We systematically investigate the influence of the amount and type of defects on the nucleation and crystallization behaviour of the $\beta$ phase using a highly selective nucleating agent and the fibre-pull technique. A discussion about the origin of the growth rate difference between the $\alpha$ - and $\beta$-phase as function of defect fraction is provided. Results obtained from the crystallization experiments are analyzed with the theory of Sanchez and Eby [22, 23].

\section{Experimental}

\subsection{Samples}

A collection of samples including one $\mathrm{ZN}$ catalysed polymer, 15 different metallocene-catalysed polymers $\left(\mathrm{M}_{\mathrm{x}}\right)$, and 5 blends $\left(\mathrm{BL}_{\mathrm{x}}\right)$ were used in this study. Table 1 gives the relevant characteristics of the individual polymers. The blends $\left(\mathrm{BL}_{\mathrm{x}}\right)$ were made by solution blending of M6 and ZN. Solutions of M6 and $\mathrm{ZN}$ in tetrachloro-ethene were prepared (10 wt $\%)$ at the solvent boiling point $\left(121.1^{\circ} \mathrm{C}\right)$ and stabilized with $0.1 \mathrm{wt} \%$ 2.6-di-tert.-butyl-4-methylphenol 99\% antioxidant (Aldrich). The hot solutions were mixed in the desired ratios. After 10 min stirring, the polymer solution was quenched in ice-water, filtered over a glass-filter, and subsequently washed with ethanol. After drying for 48 hours in a vacuum oven the blends were ready for use.

In order to determine the tacticity of the samples, ${ }^{13} \mathrm{C}-\mathrm{NMR}$ measurements were performed. The samples were prepared and measured according to the procedure described in the literature $[24,25]$. The assignment of the peaks was done using the results described in reference [26].

Number average and weight average molar masses $\left(\bar{M}_{\mathrm{n}}\right.$ and $\left.\bar{M}_{\mathrm{w}}\right)$ and polydispersity index values $\left(\bar{M}_{\mathrm{n}} / \bar{M}_{\mathrm{w}}\right)$ were determined by using gel permeation chromatography (GPC) measurements using a WatersGPC set-up equipped with a differential refractometer (Water model 410) detection system. Narrow polystyrene standards were used for calibration. Prior to the measurements, samples were dissolved in trichloro-benzene (TCB) at $130^{\circ} \mathrm{C}$ and stabilized with $0.1 \mathrm{wt} \%$ 2,6-di-tert.-butyl-4-methylphenol 99\% (Aldrich) [25].

Table 1. Molecular characteristics of samples with varying amounts of stereo defects (ZN/BL0-M5), approximately constant amount of stereo defects (M6/BL100-BL15) and varying amounts of regio- and stereo defects (BL20-M15)

\begin{tabular}{|c|c|c|c|c|c|c|}
\hline $\begin{array}{c}\text { Polymer } \\
\text { sample }\end{array}$ & $\begin{array}{l}\overline{\mathbf{M}}_{\mathrm{n}} \cdot 10^{-4} \\
{[\mathrm{~g} / \mathrm{mol}]}\end{array}$ & $\begin{array}{l}\overline{\mathbf{M}}_{\mathrm{w}} \cdot 10^{-4} \\
{[\mathrm{~g} / \mathrm{mol}]}\end{array}$ & $\begin{array}{c}\overline{\mathbf{M}}_{\mathbf{w}} / \overline{\mathbf{M}}_{\mathbf{n}} \\
{[-]}\end{array}$ & $\begin{array}{c}\text { Percentage }[\mathrm{mmmm}] \\
{[\%]}\end{array}$ & $\begin{array}{c}\text { Fraction regio defects } \\
{[-]}\end{array}$ & $\begin{array}{c}\text { Fraction stereo defects }[\mathbf{r}] \\
{[-]}\end{array}$ \\
\hline${ }^{1} \mathrm{ZN} / \mathrm{BL} 0$ & - & - & - & 98.0 & $<0.0001$ & 0.0020 \\
\hline${ }^{2} \mathrm{M} 1$ & 1.80 & 3.80 & 2.11 & 83.1 & $<0.0001$ & 0.1390 \\
\hline${ }^{2} \mathrm{M} 2$ & 4.00 & 8.10 & 2.03 & 84.2 & $<0.0001$ & 0.1460 \\
\hline${ }^{2} \mathrm{M} 3$ & 9.90 & 20.0 & 2.02 & 97.6 & $<0.0001$ & 0.0222 \\
\hline${ }^{2} \mathrm{M} 4$ & 6.80 & 20.0 & 2.94 & 97.6 & $<0.0001$ & 0.0223 \\
\hline${ }^{2} \mathrm{M} 5$ & 2.90 & 8.30 & 2.86 & 97.4 & $<0.0001$ & 0.0234 \\
\hline${ }^{3} \mathrm{M} 6 / \mathrm{BL} 100$ & - & 15.0 & - & 98.5 & 0.0034 & 0.0200 \\
\hline${ }^{3} \mathrm{M} 7$ & - & - & - & 98.0 & 0.0034 & 0.0200 \\
\hline${ }^{2} \mathrm{M} 8$ & 28.0 & 83.0 & 2.96 & 97.3 & 0.0055 & 0.0010 \\
\hline${ }^{2} \mathrm{M} 9$ & 7.50 & 26.0 & 3.47 & 97.3 & 0.0055 & 0.0010 \\
\hline${ }^{2} \mathrm{M} 10$ & - & & & 97.3 & 0.0055 & 0.0010 \\
\hline${ }^{2} \mathrm{BL} 15$ & - & - & - & 98.0 & 0.0011 & 0.0026 \\
\hline BL20 & - & - & - & 98.0 & 0.0018 & 0.0036 \\
\hline BL30 & - & - & - & 98.0 & 0.0026 & 0.0054 \\
\hline BL50 & - & - & - & 98.0 & 0.0030 & 0.0092 \\
\hline BL70 & - & - & - & 98.0 & 0.0032 & 0.0128 \\
\hline${ }^{2} \mathrm{M} 11$ & 2.00 & 3.90 & 1.95 & 84.6 & 0.0065 & 0.0920 \\
\hline${ }^{3} \mathrm{M} 12$ & 6.00 & 12.0 & 2.00 & 95.8 & 0.0027 & 0.0500 \\
\hline${ }^{3} \mathrm{M} 13$ & - & 18.0 & - & 95.0 & 0.0027 & 0.0500 \\
\hline${ }^{3} \mathrm{M} 14$ & 10.0 & 23.0 & 2.30 & 95.0 & 0.0027 & 0.0500 \\
\hline${ }^{3} \mathrm{M} 15$ & - & - & - & - & - & - \\
\hline
\end{tabular}

${ }^{1}$ DSM, Geleen, The Netherlands; ${ }^{2}$ Basell, Ferrara, Italy; ${ }^{3}$ Fina Research, Feluy, Belgium. 


\subsection{Morphology studies}

Wide angle X-ray scattering (WAXS) measurements were performed on the beam-line ID2 at the European Synchrotron Radiation Facility (ESRF). In the WAXS experiments the wavelength of the X-ray radiation was $1 \AA(\lambda=1 \AA)$. Air-scattering and detector-response were subtracted from the two-dimensional (2D) diffraction pattern. Integration over the azimuthal angle yielded the one-dimensional (1D) plot of intensity (I) versus scattering vector $(2 \theta)$. The background, taken as a straight line, was subtracted from the 1D WAXS patterns.

The relative amount of the $\gamma$-phase compared with the $\alpha$-phase was determined by WAXS. The fraction of the $\gamma$-phase $\left(\omega_{\gamma}\right)$ is best expressed using the intensity ratio of the reflections $(130)_{\alpha}\left(2 \theta \approx 12.0^{\circ}\right)$ and $(117)_{\gamma}\left(2 \theta \approx 13.1^{\circ}\right)$, respectively [27]. The areas from the $(130)_{\alpha}$ reflection $\left(A_{\alpha}\right)$ and $(117)_{\gamma}$ reflection $\left(A_{\gamma}\right)$ are used in the calculation for $\omega_{\gamma}$. Non-overlapping areas are taken as overlapping reflections may introduce extra uncertainties in the determination of the mass $\gamma$-fraction. The mass fraction of the $\gamma$ phase was then calculated by the empirical Equation (1) [28]:

$\omega_{\gamma}=\frac{A_{\gamma}}{A_{\alpha}+A_{\gamma}}$

In the rest of the paper we will denote mass fractions of the $\gamma$-phase simply as fraction.

\subsection{Crystallization studies}

Crystallization was followed using a light microscope (Olympus BX60) equipped with a CCD camera (Sony HyperHAD) and computer and polarisers. Micrographs were captured automatically by a commercially available software (Image SXM, Scion Corp.) and kept for subsequent image processing. Growth rates were determined by measuring the length of the crystalline structures (i.e. a growth front of a spherulite) with time using the captured micrographs. From the slope of the length vs. time plot growth rate values were determined. In order to reduce the statistical error, growth rate experiments were repeated at least two times and per experiment at least 5 structures were measured.

The corresponding crystallization rates of both the $\alpha$ - and $\beta$-phases were studied. Crystallization of the $\alpha$-phase was observed in non-nucleated samples. To induce the $\beta$-phase, a selective $\beta$-nucleating agent, the calcium salt of suberic acid [29] of $1000 \mathrm{ppm}$,

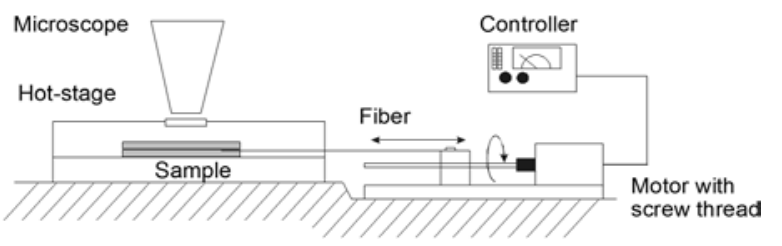

Figure 1. Schematic drawing of the fibre pull device employed for shear induced crystallization experiments

was used. The nucleant was manually dispersed into the melt. Although the $\beta$-phase could be easily distinguished from the $\alpha$-phase in most cases, the presence of $\beta$-phase crystals was always confirmed by selective melting of the $\beta$-phase prior to analyzing measured growth rates. For a typical crystallization experiment, the polymer was pressed between two glass cover-slides in a thermally controlled microscope hot stage (Mettler FP82). The polymer was kept at $220^{\circ} \mathrm{C}$ for $5 \mathrm{~min}$ to remove the thermal-rheological history and then cooled to the temperature of crystallization $\left(130^{\circ} \mathrm{C}\right)$ within approximately $1 \mathrm{~min}$. Subsequently, the polymer was cooled down to $110^{\circ} \mathrm{C}$ and heated up from 110 to $180^{\circ} \mathrm{C}$ with $10^{\circ} \mathrm{C} / \mathrm{min}$ in order to the study the aforementioned selective melting of the $\beta$-phase.

Shear-induced crystallization experiments were performed with the help of a fibre pull device (Figure 1). In this device a fibre was pulled at a controlled rate $\left(v_{\text {pull }}\right)$ for a predetermined time $\left(t_{\text {pull }}\right)$. The fibre was sandwiched between two thin solid polymer films. The two polymer films together with the fibre are placed between two cover-slides and melted. As in normal quiescent crystallization experiments, the polymer was kept at $220^{\circ} \mathrm{C}$ for 5 min to remove the thermal-rheological history and then cooled to the temperature of crystallization $\left(T_{\mathrm{c}}=\right.$ $130^{\circ} \mathrm{C}$ ) within approximately $1 \mathrm{~min}$. Upon reaching $T_{\mathrm{c}}$ the fibre was pulled. The temperature of pulling ( $\left.T_{\text {pull }}\right)$ was set to be equal to $T_{\mathrm{c}}$. The course of crystallization was followed by PLM as in the case of quiescent crystallization.

\section{Results}

In this section the results of this research are arranged as follows. The section starts with a short description of the samples. We show the possible defect structures present in the samples and characterize the amount of defects by defect-fractions. Next, we describe the dependence of the amount of the various polymorphs on the amount and type of 
the defects. The section proceeds with the presentation of the results obtained from crystallization experiments. A description of the growth rates of both the $\alpha$-phase and $\beta$-phase as a function of the number and type of defects is given. The section ends with a discussion of the results regarding the formation of the $\beta$-phase under shear.

\subsection{Description of defects}

Table 1 shows the main characteristics of the samples used in this research. The polymer samples show a large diversity in chain regularity. The regularity or the configuration of successive stereo centres (chiral carbon atoms) in the isotactic iPP chain determines the overall order (tacticity) of the polymer. Theoretical predictions were essentially made for polymers with randomly distributed defects. Therefore it is important to make use of polymers with only randomly distributed defects. The samples mentioned in Table 1 are predominantly metallocene catalysed iPPs with different chain-architectures in which the defects are distributed evenly and randomly in the chains. Identification and quantification of the defects are necessary in order to investigate the influence of chain architecture on the melting and crystallization of the polymer. With help of ${ }^{13} \mathrm{C}$ -NMR the sequence length on the pentad level [21] was determined. Since we are interested in the fraction of stereo-defects, denoted as the racemic diad $[r]$, we need to calculate $[r]$ from the measured pentad fractions. This was done according to the method described in literature [30]. The results are given in Table 1. We assume a similar influence of the many possible stereo sequence defects on crystallization behaviour of iPP, therefore we decided to take the fraction racemic $[r]$ additions as a measure for the number of stereo-defects. The fraction of stereo-defects presented in Table 1, is thus a collection of all the possible stereo errors, no discrimination was made for the possible variations of stereosequences in the chain. We believe, that although this may be an oversimplification, it is a very powerful way of dealing with all given polymer samples in a combined fashion. In addition to the stereodefects, the polymer chain may also contain regiodefects. Regio-defects are defined as a mis-insertion of the propylene unit in the chain [30], usually denoted as a 2,1 addition. The results of the quantification of the regio-defect fraction as measured by ${ }^{13} \mathrm{C}$-NMR are also given in Table 1 .
In order to facilitate the analyses, the samples in Table 1 were sorted in three groups. The first group of samples (Group 1) contains polymers with only stereo-defects (ZN, M1-M5). No regio-defects are present in these samples. The second group (Group 2) contains polymers with a low amount of stereodefects, but with a strong varying amount of regiodefects (M3-M10). The third group (Group 3) contains polymers with both significant amounts of stereo- and regio-defects (BL15-M15). By dividing the polymers in these 3 groups it is possible to separately investigate the influence of stereo- and regio-defects on the crystallization behaviour and morphology.

\subsection{Polymorphic composition of the samples as observed by WAXS}

As mentioned above, the formation of the $\gamma$-phase is enhanced with the incorporation of defects within the chain. Especially in metallocene catalysed iPPs an increase in the amount of the $\gamma$-phase can be found. In order to investigate the influence of stereoand regio-defects on the formation of the $\gamma$-phase, WAXS experiments were performed. Each sample was crystallized isothermally at $130^{\circ} \mathrm{C}$ and rapidly cooled to room temperature. The WAXS measurements were performed at room temperature.

To qualitatively show the influence of chain defects on the formation of the $\gamma$-phase, WAXS diffractograms (Figure 2) are given for a given number of polymers with increasing defect fraction (ZN, BL70, BL30, BL15, and M11), see Table 1. Included in the figure are the most (M11) and least (ZN) defected polymers (upper and lower curves, respectively). For all polymers the characteristic (117) $\gamma$ reflection is present, including the $\mathrm{ZN}$ catalysed iPP with the least defects, although for the latter with very weak intensity. As expected, the intensity of the (117) $\gamma$ reflection strongly increases with defect fraction, while the intensity of the $(130)_{\alpha}$ reflection decreases. The increase in the amount of the $\gamma$-phase can also be seen in the increasing intensity of the small $(113)_{\gamma}$ peak indicated by the arrow.

The amount of the $\gamma$-phase $\left(\omega_{\gamma}\right)$ is quantified by the ratio of the relative areas of the (117) $\gamma$ and $(130)_{\alpha}$ reflections. The percentage of crystals exhibiting the $\gamma$-phase $\left(\omega_{\gamma}\right)$ is plotted as a function of defect fraction, in Figure 3. The different specimens were grouped and plotted according to the specific defect 


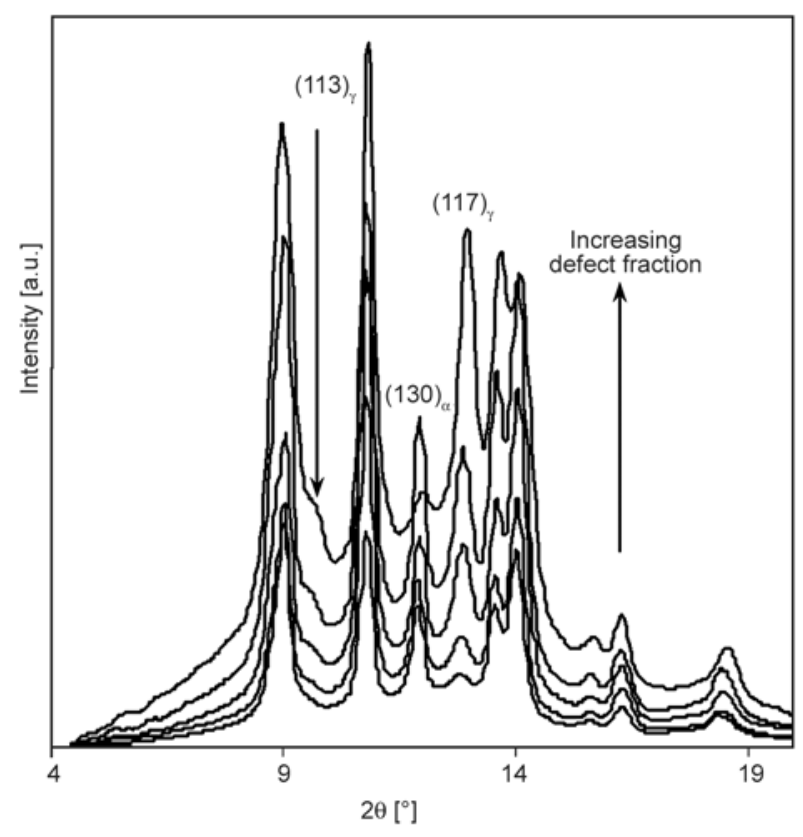

Figure 2. WAXS diffractograms of several iPP polymers $(\alpha / \gamma$-phase) with increasing defect fraction (from bottom to top) obtained after complete crystallization. Explanation of peaks indicated can be found in the text.

type as function of the type of the given defect fraction, i.e. the amount of the $\gamma$-phase of the polymers: (1) with only stereo-defects (ZN, M1-M5) ( $\boldsymbol{\Delta})$ is plotted as function of the fraction stereo-defects (Group 1);

(2) with varying fraction of regio-defects (M3M10) (घ) but with approximately the same fraction of stereo-defects is plotted as function of fraction regio-defects (Group 2);

(3) with both stereo- and regio-defects (BL15M15) (O) is plotted as function of fraction stereo-defects [31] (Group 3).

We saw already qualitatively that the fraction of the $\gamma$-phase increases with increasing number of defects. Data from Figure 3 quantifies this result. As Figure 3 shows a much stronger increase of the $\gamma$-phase as a function of increasing regio-defect fraction as compared to the amount of stereo-defects. This conclusion is in disagreement with an earlier published result that the two types of defects (regio/ stereo) have the same influence on the formation of the $\gamma$ polymorphic form of iPP [32].

Under the crystallization conditions employed, the $\gamma$-phase percentage increases up to $93 \pm 5 \%$ [33] for the polymer with the highest fraction of defects. The polymer with the lowest fraction of defects, i.e. the polymer synthesized by a $\mathrm{ZN}$, contains approximately $7 \pm 5 \%$ [33] $\gamma$-phase, which is still consider-

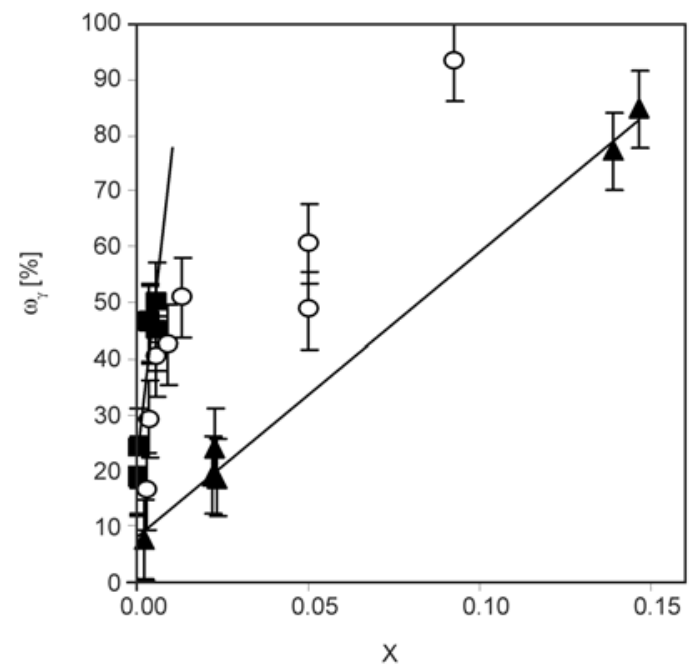

Figure 3. Fraction of the $\gamma$-phase of the polymer sample studied as a function of defect fraction. Assignments of the symbols are given in the text. The error bars are estimated errors of $5 \%$.

able. As one can see, Figure 3 shows two approximately linear dependences on the number of regioand stereo-defects, respectively. The observed relationships between the percentage of the $\gamma$-phase as a function of the two different types of defects (regio/ stereo) were fitted with a linear relationship using a standard least-squares fit procedure. The following numerical equations were obtained (Equation (2) and (3)):

$\left(\omega_{\gamma, \mathrm{s}}\right)_{\mathrm{X}_{\mathrm{r}}=0}=(8.3 \pm 1.6)+(5.1 \pm 0.2) \cdot 10^{2} X_{\mathrm{s}}$

$\left(\omega_{\gamma, \mathrm{r}}\right)_{\mathrm{X}_{\mathrm{s}} \approx 0}=(22.2 \pm 3.0)+(5.3 \pm 0.9) \cdot 10^{2} X_{\mathrm{r}}$

where $\left(\omega_{\gamma, s}\right)_{X_{\mathrm{r}}=0}$ corresponds to the percentage of the $\gamma$-phase as function of stereo-defects, while the fraction of the regio-defects was kept zero. $X_{\mathrm{s}} \approx 0$ in the subscript of Equation (3) refers to approximately zero fraction of stereo-defects for the equation fitted with the amount of regio-defect fraction used as independent variable (Equation (3)). A linear combination of Equation (2) and (3) yields the Equations (4) and (5):

$\omega_{\gamma, \mathrm{s} / \mathrm{r}}=(8.3 \pm 1.6)+(5.1 \pm 0.2) \cdot 10^{2} \widetilde{X}$

where $\widetilde{X}=X_{\mathrm{s}}+(10.3 \pm 1.5) X_{\mathrm{r}}$

The combined defect fraction $(\widetilde{X})$ is the sum of the number of stereo-defects and the number of regiodefects multiplied by a given weighting factor with a value of 10.3. Equation (4) and (5) predicts a linear relationship between the amount of the $\gamma$-phase 
with the combined defect fraction $(\widetilde{X})$. Figure 4 shows the percentage $\gamma$-phase as a function of $\widetilde{X}$ for all polymers mentioned in Table 1 . We see that the formation of the $\gamma$-phase is approximately linear with the combined defect fraction $(\widetilde{X})$. Equations (4) and (5) predict that the percentage of the $\gamma$ phase will be $100 \%$ at a combined defect fraction of $\widetilde{X} \approx 0.17$. Equations (2)-(5) are strictly valid for values of $\widetilde{X}<0.17$ or for $\omega_{\gamma, \mathrm{s}}<100 \%$.

Although a linear fit is used to describe the observed percentage of the $\gamma$-phase as function of the combined defect fraction, a higher order (e.g. a second order) polynomial would fit the trend more accurately (see the dashed trend line in Figure 4). In the calculation of Equation (4) and (5) we assumed a linear dependence of the amount of the $\gamma$-phase for both the regio- and stereo-defects. Probably this assumption is not entirely valid and a higher-order dependence describing the relationship between the fraction of regio-defects (or stereo-defects) and the percentage of the $\gamma$-phase would yield a better fit with the observed data. Nevertheless, the data presented in Figure 4 clearly show that the amount of the $\gamma$-phase strongly depends on the amount of regio- and stereo-defects, exhibiting a stronger function on the fraction of regio-defects.

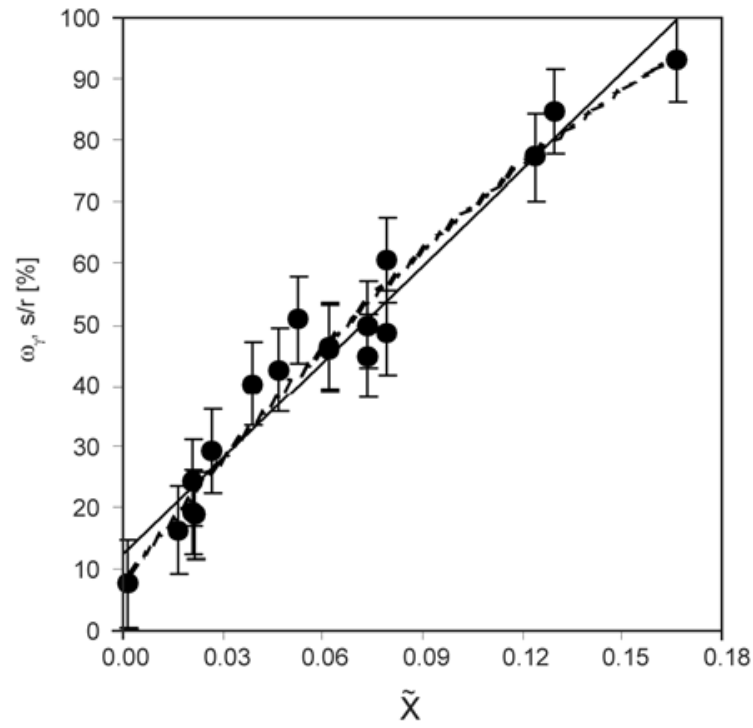

Figure 4. Fractions of the $\gamma$-phase of the used polymers as a function of combined defect fraction. Assignments of the symbols are given in the text. Error bars correspond to estimated errors of $5 \%$.

\subsection{Polymorphism and chain architecture ( $\beta$-phase)}

From the literature it is known that only negligible amounts of the $\beta$-phase forms in random (ethylene/ propylene) copolymers with low (1.8-2.5\%) ethylene content [12]. Based on these observations, it was suggested that the tendency to $\beta$-crystallization is suppressed by the disturbance of the chain regularity $[13,34]$. As we have access to a large set of PP samples with various types and amounts of chain defects, the opportunity arose to perform a comprehensive structure-property study on the formation of the $\beta$-phase and its dependence on the chain architecture.

To demonstrate the decrease in the tendency for $\beta$ crystallization with the incorporation of defects in the chain, WAXS measurements were performed. Two peaks in the WAXS diffractograms of iPP are characteristic for the $\beta$-phase, i.e. $(300)_{\beta}$ at $2 \theta=10.4^{\circ}$ and $(311)_{\beta}$ at $2 \theta=13.8^{\circ}$ diffraction angle, respectively. Figure 5 shows the WAXS diffractograms for a selective number of polymers with increasing defect fraction (ZN, BL70, BL30, BL15, M12). The arrows in Figure 5 show the strong decrease in intensity of the characteristic peaks. Thus, the amount of

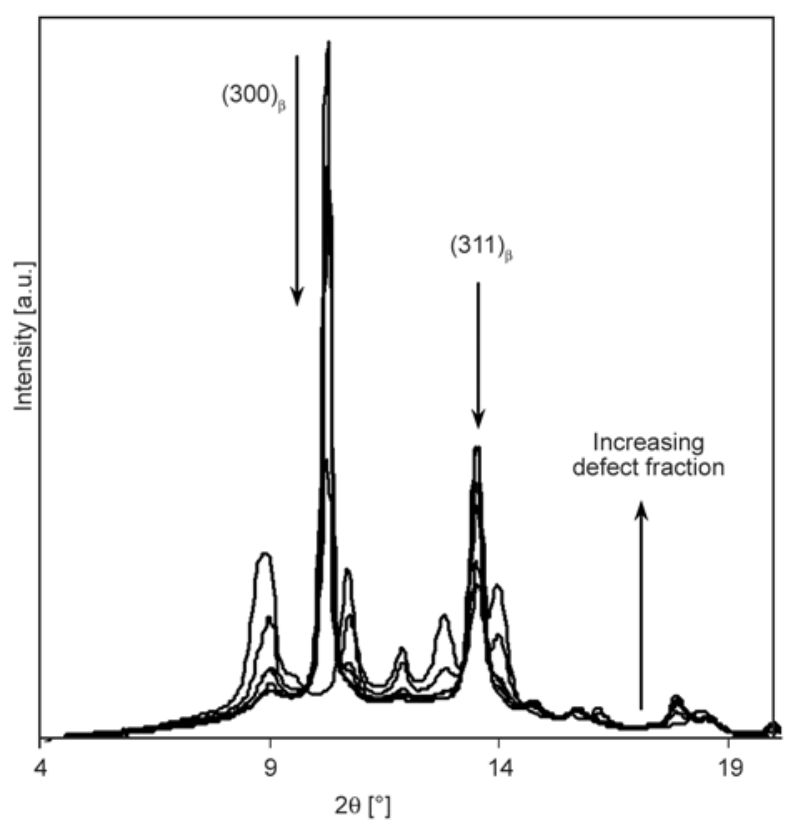

Figure 5. WAXS diagrams of several iPP polymers (characteristic reflections for the $\beta$-phase are labelled) with increasing defect fraction obtained after complete crystallization. Explanation of the peaks indicated can be found in the text. 
the $\beta$-phase strongly decreases with increasing fraction of defects. The $\beta$-phase was present in relative high amounts only in polymers with relatively low amounts of defects (ZN, M1-M4, and BL15-BL30). In the next section we will see that separate peaks from SAXS can be detected only for the polymers with considerable $\beta$-phase formation.

Several reasons exist why the amount of the $\beta$-phase strongly decreases with increasing concentration of defects. The amount of the $\beta$-phase is kinetically determined and depends on the relative growth rates of the $\alpha$-phase and the $\beta$-phase $\left(G_{\alpha}\right.$, and $\left.G_{\beta}\right)$, respectively. At the crystallization temperature of $130^{\circ} \mathrm{C}$, $G_{\alpha} / G_{\beta}$ is smaller than unity for conventional ZN catalysed iPPs [35]. However, this ratio increases rapidly with increasing fraction of defects and becomes even larger than unity above some critical defect concentration. Once nucleated, the $\beta$-phase is easily overgrown by the $\alpha$-phase if the growth rate of the $\alpha$-phase is higher $\left(G_{\alpha}>G_{\beta}\right)$. Consequently, the growth of the $\beta$-phase is increasingly restricted with increasing defect fraction.

Another factor determining the fraction of the $\beta$ phase originates from the use of a $\beta$-nucleating agent. Assuming that the $\beta$-phase epitaxially nucleates [36] on the surface of the nucleant, it is expected that epitaxial nucleation will be disturbed by the presence of defects. An increase in the amount of defects, therefore, reduces the efficiency of the nucleant.

\subsection{Growth rate measurements by PLM}

In this section we describe the isothermal growth kinetics of the samples used. The growth rate of crystallization $(G)$ was monitored by measuring the increase of the spherulitic diameter in the radial direction as a function of time. The spherulite size increased linearly with time and remained linear over the measured time. The growth rates of both $\alpha$ and $\beta$-phases of the $\mathrm{ZN}$ sample (indicated by 1 , Figure 6$)$ are larger compared with the growth rates $(\alpha-$ and $\beta$-phases) measured for the more defected sample M9 (indicated by 2). We see that the growth rate of the $\beta$-phase clearly exceeds the growth rate of the $\alpha$-phase for the $\mathrm{ZN}$-sample. Furthermore, for the sample M9 the growth rates of the $\beta$ - and $\alpha$-phases are approximately the same. These results indicate that the absolute growth rates depend on the number (and type) of defects and that the $\beta$-phase shows a stronger dependence on the number (and type) of defects than the $\alpha$-phase.

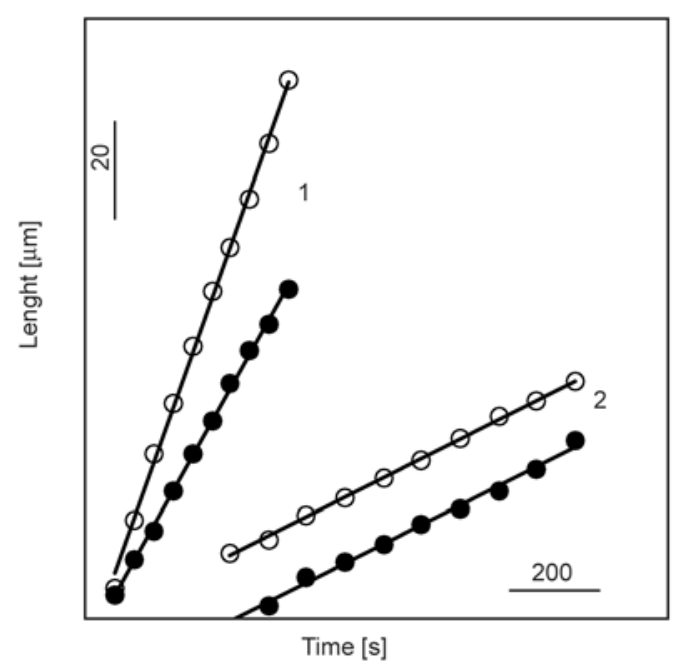

Figure 6. The spherulitic diameter as a function of time for the samples ZN (1) and M9 (2) at the crystallization temperature of $130^{\circ} \mathrm{C}$. Open circles (०) represent the $\beta$-phase, closed circles $(\bullet)$ originate from the $\alpha$-phase.

No influence of the molar mass on the spherulitic growth rate could be detected for the molar mass range studied here. For example, the polymers M9 and M10 with similar chain characteristics but different molar masses $\left(8.25 \cdot 10^{5}\right.$ and $2.55 \cdot 10^{5} \mathrm{~g} / \mathrm{mol}$, respectively) show very similar growth rates $(0.037$ and $0.035 \mu \mathrm{m} / \mathrm{s}$, respectively).

\subsection{Growth rates of the $\alpha$ - and $\beta$-phases}

Growth rates $(G)$ were determined for all samples mentioned in Table 1 at the crystallization temperature of $130^{\circ} \mathrm{C}$. Linear growth rates with time were found for all polymers. Figure 7 shows the values of $\ln G$ of iPP ( $\alpha$-phase) as a function of defect fraction. In principle, we measured the growth rates of spherulites consisting of the $\alpha$-phase, but at the same time an increase in the amount of $\gamma$-phase was detected in samples with increasing defect fraction. As the formation of the $\gamma$-phase is related to the presence of the $\alpha$-phase, it was not possible to separately measure the growth rates of the $\alpha$ - and $\gamma$ phases. Therefore, in the rest of this section we denote the growth rate of spherulites exhibiting both the $\alpha$ - and $\gamma$-phases as $G_{\alpha}$.

The $\ln G$ of specimen with the different types of dominating defects (regio- or stereo-defects) were plotted according to a specific defect type as function of that defect fraction. The growth rates of the polymers:

(1) with only stereo-defects (ZN, M1-M5) ( $\mathbf{\Delta})$ are plotted as function of the fraction stereo-defects (Group 1); 


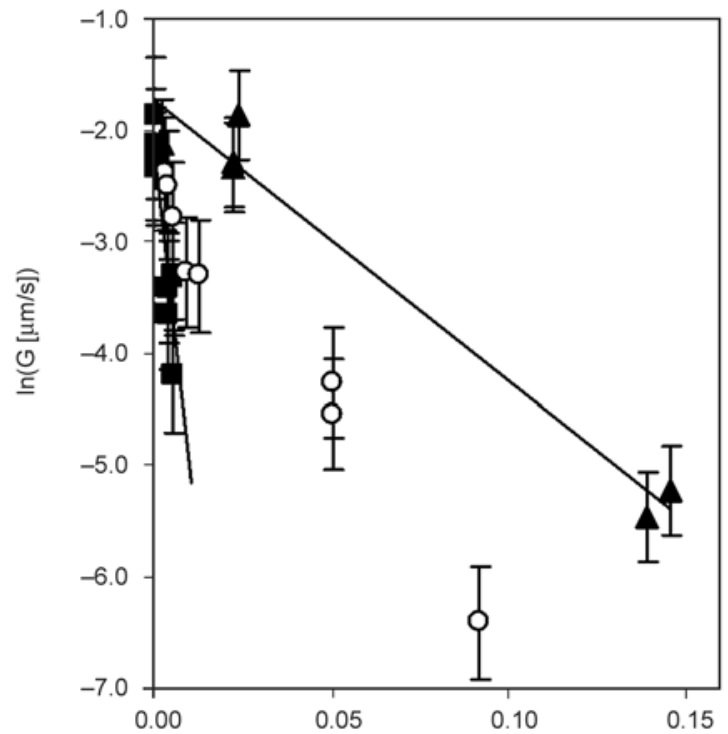

a) $x$

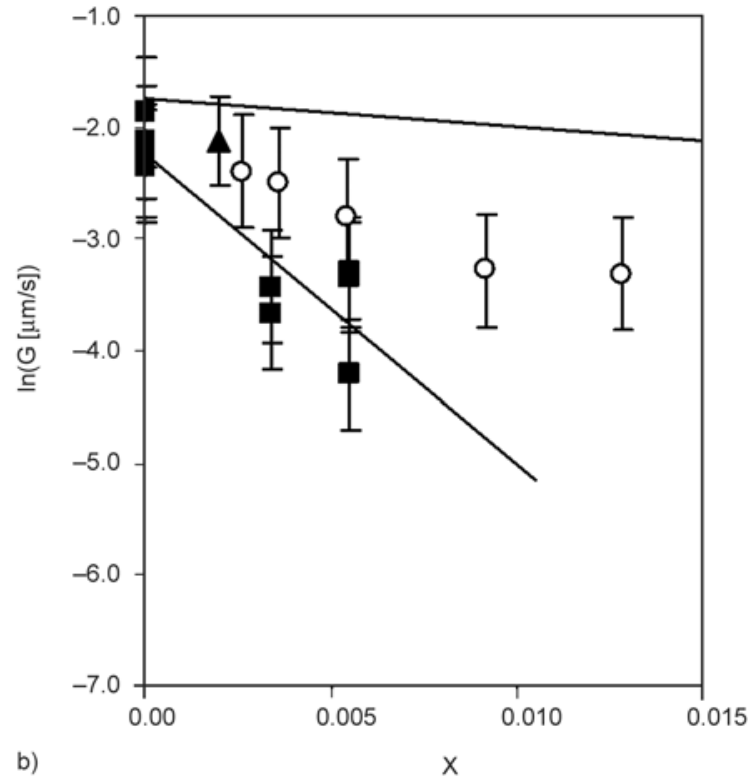

b)

Figure 7. (a) Growth rates of the $\alpha$-phase as a function of the defect fraction. (b) Magnification of a section showed in (a) for low defect fractions. The solid lines are fitted lines using a least squares fit through the data points. Assignments of symbols are given in the text.

(2) which show a variation in the fraction regiodefects (M3-M10) (匹) but exhibit approximately the same fraction of stereo-defects are plotted as function of fraction regio-defects (Group 2);

(3) with both stereo- and regio-defects (BL15-M15) ( $\circ)$ are plotted as function of fraction stereodefects (Group 3).

Figure 7 shows a decrease in growth rate for all samples with increasing defect fraction. The growth rates of samples with a varying amount of regio-defects but constant amount of stereo-defects (Group 2) show a much stronger dependence on the number of defects than the growth rates of the samples with only a varying amount of stereo-defects.

As can be seen in Figure 7, two trend lines are given. One trend line shows the linear dependence of the growth rate as function of stereo-defects, while the other shows the linear dependence of the growth rate as function of regio-defects, respectively. The two trend lines can be presented as two linear equations (Equation (6) and (7)):

$$
\begin{aligned}
& \ln \left(G_{\alpha, \mathrm{s}}\right)_{\mathrm{X}_{\mathrm{r}}=0}=-(2.5 \pm 0.2) \cdot 10^{1} \cdot X_{\mathrm{S}}-(1.74 \pm 0.22) \\
& \ln \left(G_{\alpha, \mathrm{r}}\right)_{\mathrm{X}_{\mathrm{S}} \approx 0}=-(2.8 \pm 0.5) \cdot 10^{2} \cdot X_{\mathrm{r}}-(2.23 \pm 0.19)
\end{aligned}
$$

where $\ln \left(G_{\alpha, \mathrm{s}}\right)_{\mathrm{X}}=0$ corresponds to the logarithm of the growth rate of the $\alpha$-phase as function of stereodefects with zero fraction of regio-defects.
In order to describe also the group of polymers that exhibit a variation in both stereo- and regio-defects (०) a linear combination of Equations (6) and (7) was made. The linear combination results in the Equation (8):

$$
\begin{aligned}
\ln G_{\alpha, \mathrm{s} / \mathrm{r}}= & -(2.5 \pm 0.2) \cdot 10^{1} \cdot X_{\mathrm{s}}-(2.8 \pm 0.5) \cdot 10^{2} \cdot X_{\mathrm{r}}- \\
& -(1.74 \pm 0.22)
\end{aligned}
$$

which can be further simplified to Equation (9) and (10):

$\ln G_{\alpha, \mathrm{s} / \mathrm{r}}=-(2.5 \pm 0.2) \cdot 10^{1} \cdot \widetilde{X}-(1.74 \pm 0.22)$

where $\widetilde{X}=X_{\mathrm{s}}+(11.1 \pm 3.1) X_{\mathrm{r}}$

As described earlier, a combined defect fraction $(\widetilde{X})$ is introduced. $\widetilde{X}$ is the sum of the number of stereodefects and the number of regio-defects multiplied by a given regio-error coefficient with a certain value. The value of regio-error coefficient (11.1 \pm 3.1$)$ was calculated using an error propagation estimation. The combined defect fraction provides us with the possibility to describe any sample with an arbitrary amount of stereo- and regio-defects with a single parameter. The regio-error coefficient is a measure for the (stronger) influence of regio-defects on the rate of crystallization.

The growth rate of the $\beta$-phase $\left(G_{\beta}\right)$ as function of the number and type of defects was measured, as well. Similar to Figure 7 for the $\alpha$-phase Figure 8 

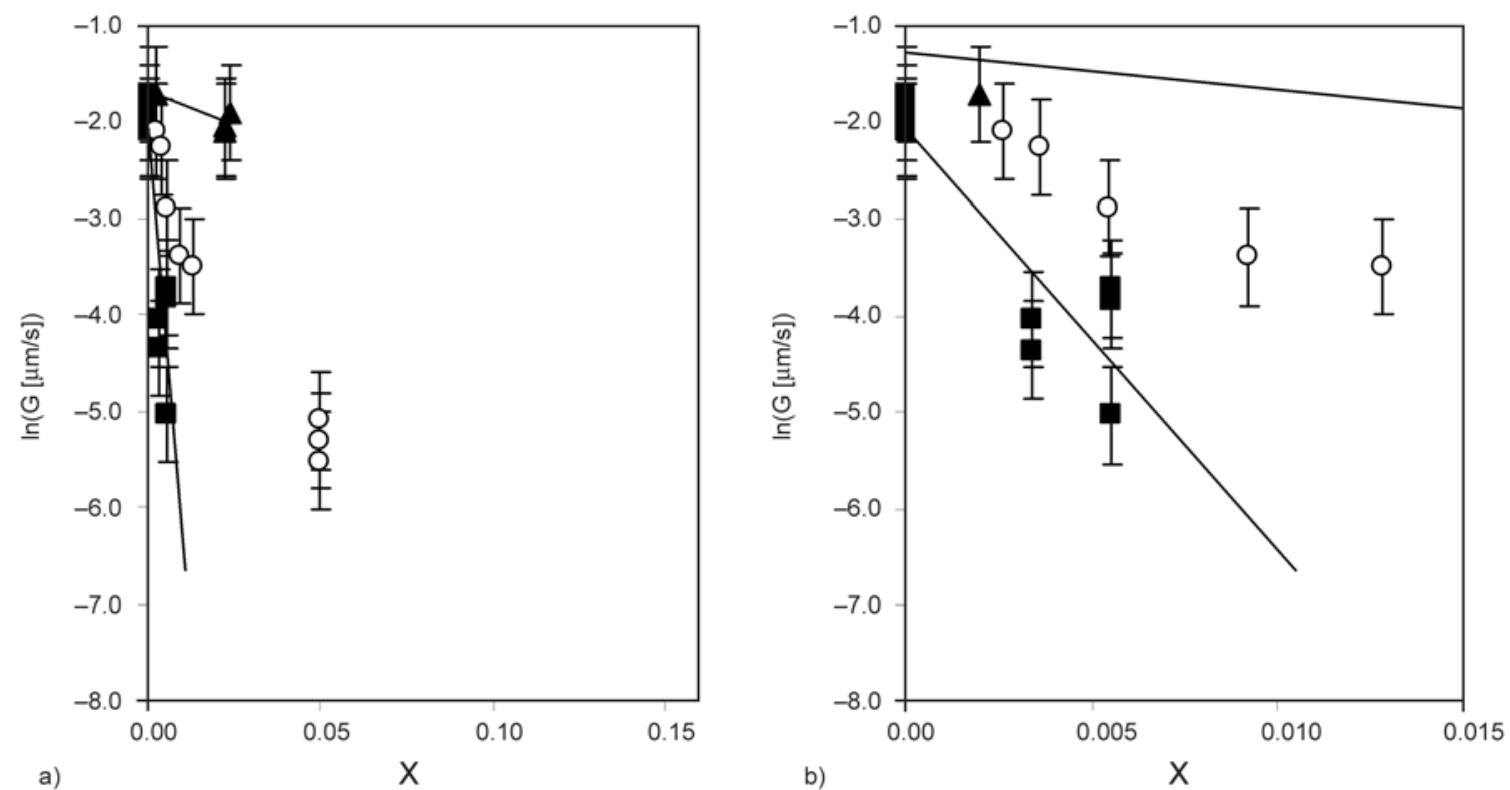

Figure 8. (a) $\ln G$ of the $\beta$-phase for various samples as a function of the fraction of defects. The figure to the right (b) shows the dependence of the defect fractions with enlarged $x$-scale. The solid lines are fitted through the data points. Assignments of symbols are given in the text.

gives the natural logarithm of the growth rate of the $\beta$-phase $\left(\ln G_{\beta}\right)$ as a function of defect fraction. The polymers with different types of defects were grouped as it was done for the $\alpha$-phase.

The linear dependence of $\ln G_{\beta}$ on the amount of regio-defects can be written in the following form (Equation (11)):

$$
\ln \left(G_{\beta, \mathrm{r}}\right)_{\mathrm{X}_{\mathrm{S}} \approx 0}=-(4.4 \pm 0.8) \cdot 10^{2} \cdot X_{\mathrm{r}}-(2.1 \pm 0.3)
$$

As one can see from Equation (7) and Equation (11), the values of the slopes are $-2.8 \cdot 10^{2}$ and $-4.4 \cdot 10^{2}$ for the $\alpha$ - and $\beta$-phase, respectively. In addition to the general larger influence of the regio-defects on the growth rate, the influence of regio-defects on the growth rate of the $\beta$-phase is much larger as compared with the growth rate of the $\alpha$-phase. Unfortunately, the growth rates of the polymers with the highest defect concentrations could not be determined at the crystallization temperature of $130^{\circ} \mathrm{C}$. The lowest growth rate for the $\beta$-phase, which was possible to directly measure, was approximately $0.0039 \mu \mathrm{m} / \mathrm{s}$. For the samples with the highest defect fractions the relative growth rate of the $\alpha$ phase compared with the $\beta$-phase was much higher. Therefore, a growing $\beta$-phase crystal was readily surrounded and overgrown by $\alpha$-phase crystals. Moreover, the nucleating ability of the $\beta$-nucleants to induce the $\beta$-phase decreased with an increasing amount of defects, which resulted in a practically undetectable amounts of the $\beta$-phase for these samples. Therefore the determination of the $\beta$-phase growth rate at $130^{\circ} \mathrm{C}$ for samples with the highest defect concentrations (M1) was done indirectly. The indirect method involved the measurement of the crystal growth rates of the $\beta$-phase at lower crystallization temperatures $\left(105^{\circ} \mathrm{C}<T_{\mathrm{c}}<120^{\circ} \mathrm{C}\right)$ followed by an extrapolation to the crystallization temperature of $130^{\circ} \mathrm{C}$. Figure $9 \mathrm{a}$ shows the results of the growth rates as function of various crystallization temperatures. The line through the measurement points is extrapolated to $130^{\circ} \mathrm{C}$ and gives the value of $\ln G=-6.6$ at $130^{\circ} \mathrm{C}$. This value of the growth rate is plotted in Figure $9 \mathrm{~b}$. In the figure the solid line is fitted using the data points, and exhibits a slope of $3.8 \cdot 10^{1}$.

We assume that $\ln G_{\beta}$ has a linear dependence on $X_{\mathrm{s}}$; thus we can write Equation (12):

$\ln \left(G_{\beta, \mathrm{s}}\right)_{\mathrm{X}_{\mathrm{r}}=0}=-(3.8 \pm 0.2) \cdot 10^{1} \cdot X_{\mathrm{s}}-(1.28 \pm 0.16)(12)$

Since we know the dependence of $\ln G_{\beta}$ on the amount of regio-defects (Equation (11)) and stereodefects (Equation (12)), it is possible to combine these equations as was done for the $\alpha$-phase (see Equation (9) and (10)) resulting in Equation (13) and (14):

$$
\begin{aligned}
& \ln G_{\beta, \mathrm{s} / \mathrm{r}}=-(3.8 \pm 0.2) \cdot 10^{1} \cdot \widetilde{X}-(1.28 \pm 0.16) \\
& \text { where } \widetilde{X}=X_{\mathrm{s}}+(11.6 \pm 2.8) X_{\mathrm{r}}
\end{aligned}
$$



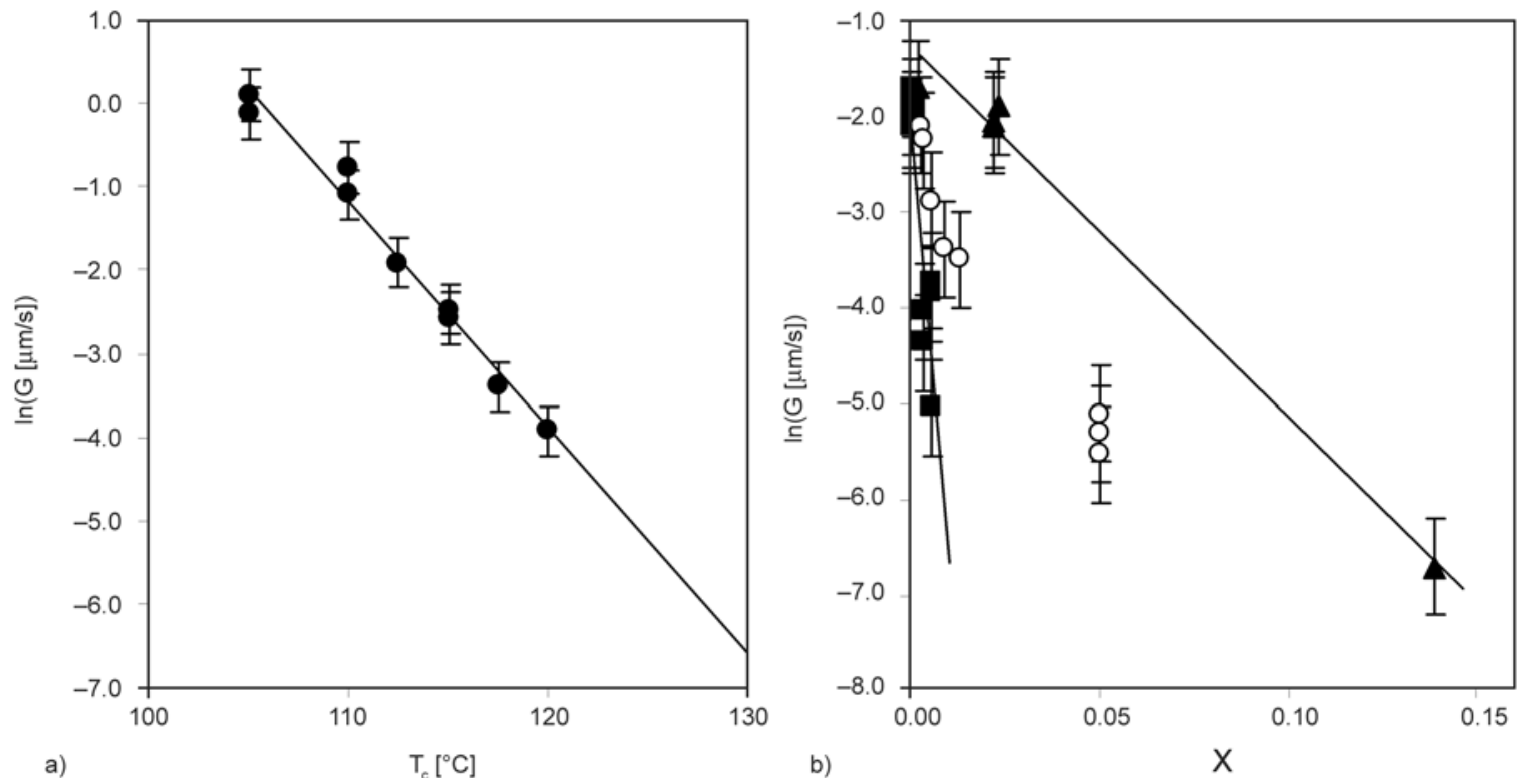

Figure 9. (a) $\ln G$ of the $\beta$-phase for sample M1 as a function of crystallization temperature $\left(T_{\mathrm{c}}\right)$. The figure to the right (b) shows $\ln G$ of the $\beta$-phase for various samples as a function of the fraction of defects (=Figure $8 \mathrm{a}$ ). The solid lines are fitted through the data points. Assignments of symbols are given in the text.

The regio-error coefficients of the $\alpha$ - and $\beta$-phases show a remarkable resemblance. In both equations the influence of the regio-defects on the growth rate is approximately 11-12 times higher than for the stereo-defects. Comparing Equation (9) and (13) we can draw the conclusion that the influence of stereodefects on the growth rate of the $\beta$-phase is larger as compared to the influence of stereo-defects on the $\alpha$-phase. We already drew the conclusion that the influence of regio-defects on the growth rate of the $\beta$-phase is larger as compared to the influence of regio-defects on the $\alpha$-phase.

Although regio-defects have a larger influence on the crystallization rate of $\beta$-phase as compared to the $\alpha$ phase, regio-defects compared with stereo-defects exert a similar influence on the growth rate of the $\alpha$ and $\beta$-phases, respectively. In other words, the influence of the number of (stereo- and regio-) defects on the growth rate of the $\beta$-phase is a constant factor larger as compared with the $\alpha$-phase.

The use of the combined defect fraction $(\widetilde{X})$ provides us with the possibility to describe any sample with an arbitrary amount of stereo- and regio-defects. Utilizing this possibility the growth rate data of all samples mentioned in Table 1 (for both the $\alpha$ - and $\beta$-phases) was plotted as function of the combined defect fraction. This procedure resulted in Figure 10. Clearly, $G_{\beta}$ is higher than $G_{\alpha}$ at zero combined defect fraction, however, with increasing defect fraction $G_{\beta}$ decreases stronger than $G_{\alpha}$ as a function of $\widetilde{X}$. At

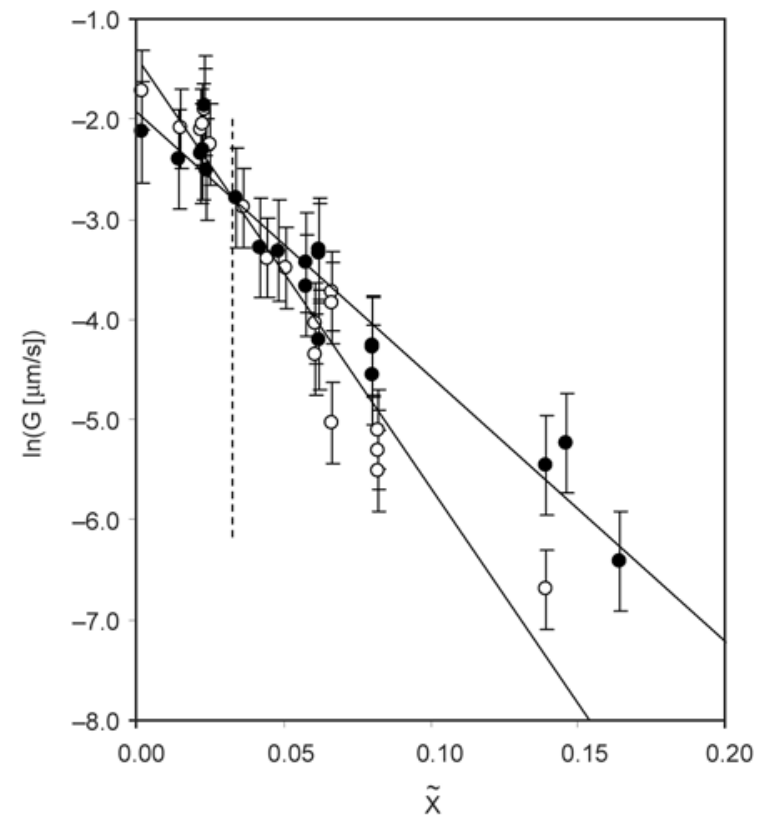

Figure 10. Growth rates as a function of the combined defect fraction. Open symbols $(\circ)$ : growth data for the $\beta$-phase. Closed symbols $(\bullet)$ : growth data for the $\alpha$-phase.

approximately $\widetilde{X}=0.03$ a cross-over takes place, which is characterized by an equal growth rate of the $\alpha$ - and $\beta$-phase $\left(G_{\beta}=G_{\alpha}\right)$. According to the literature, equal growth rates for both phases take place at a critical $\beta \alpha$-crystallization temperature $\left(T_{\beta \alpha}\right)$ of $140^{\circ} \mathrm{C}$ for virtually defect-free samples $[13,35]$. This critical temperature was determined using highly isotactic (ZN catalysed) iPP samples. At a 
crystallization temperature $T_{\mathrm{c}}=130^{\circ} \mathrm{C}$ and at a combined defect fraction of 0.03 the growth rates for the $\alpha$ - and $\beta$-phases are equal. Consequently, for samples exhibiting a combined defect fraction of 0.03 the $T_{\beta \alpha}$ is lowered from 140 to $130^{\circ} \mathrm{C}$.

\subsection{The shear induced formation of the $\beta$-phase}

The relative growth rates of the $\alpha$ - and $\beta$-phases are important for the formation of the $\beta$-phase. A lowering of the $T_{\beta \alpha}$ has a profound influence on the formation of the $\beta$-phase under shear. In the previous section we saw that at the crystallization temperature of $130^{\circ} \mathrm{C}$ the ratio of $G_{\beta} / G_{\alpha}$ decreases with increasing defect fraction and above $\widetilde{X} \approx 0.03, G_{\beta}<G_{\alpha}$. In this section we study the consequences of the decreasing $\beta \alpha$-recrystallisation temperature $\left(T_{\beta \alpha}\right)$ on the formation of the $\beta$-phase under shear conditions.

A cylindritic morphology is formed by crystallization of a melt under mechanical load (shear, elongation). The mechanical load can be introduced by pulling a fibre through an undercooled melt at a certain temperature $T_{\text {pull }}$. The shear stress generated by fibre pulling produces row nuclei consisting of the $\alpha$-phase that induce the growth of a cylindritic growth front $[13-19,37]$. These row nuclei surround the fibre in a cylindritic fashion thus the growth front is cylindrical and proceeds in the radial direction. The row nuclei likely consist of extended chain crystals $[13,19,38]$ which act as nucleants for the $\beta$-phase. On these structures, if $G_{\beta}>G_{\alpha}, \beta$-phase crystallites can nucleate (although at a lower nucleation density as compared with the nucleation density of the $\alpha$ phase). Figure 11 gives a schematic representation of such a cylindritic morphology.

In typical shear-induced crystallization experiments performed in this research, a fibre was pulled at a controlled rate $\left(v_{\text {pull }}\right)$ for a predetermined time $\left(t_{\text {pull }}\right)$.

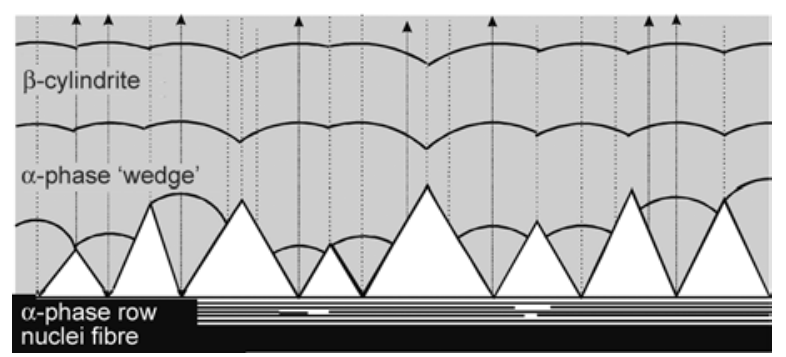

Figure 11. Schematic representation of the cylindritic morphology according to the Varga-Karger Kocsis model $[19,38]$. The arrows indicate the direction of growth front.
The polymer was kept at $220^{\circ} \mathrm{C}$ for $5 \mathrm{~min}$ to remove the thermal-rheological history and then cooled to the temperature of crystallization $\left(T_{\mathrm{c}}=130^{\circ} \mathrm{C}\right)$ within approximately $1 \mathrm{~min}$. The temperature of pulling ( $\left.T_{\text {pull }}\right)$ was set to be equal to $T_{\mathrm{c}}$. The formation of the cylindritic morphology was followed with PLM. Figure 12 shows typical microstructures as revealed by PLM of two fibre-pull experiments in which the time of pulling ( $\left.t_{\text {pull }}\right)$ was varied ( 1 and $8 \mathrm{~s}$, respectively). The $\beta$-cylindritic structure as schematically presented in Figure 11. can be clearly seen in Figure 12b. An $\alpha$-phase 'wedge' is indicated with a white arrow. Due to the variation in $t_{\text {pull, }}$, the morphology shows several differences, which can be best seen at the upper side of the fibre. The number of $\beta$-nuclei $\left(\mathrm{N}_{\beta}\right)$ is much lower after a shorter shear time $(1 \mathrm{sec})$. The $\alpha$-phase grows much longer unperturbed as can be seen by the larger 'wedges' (arrow in Figure 12b). In case of higher shearing times $\left(t_{\text {pull }}\right)$ more $\beta$-nuclei $\left(\mathrm{N}_{\beta}\right)$ are generated, and as a consequence the $\alpha$ phase 'wedges' are smaller.

From the PLM-micrographs we could quantify the number of $\beta$-nuclei $\left(\mathrm{N}_{\beta}\right)$. This was done by counting the number of 'wedges' for a certain length of the fibre. The length of the fibre for which the number of nuclei was counted was chosen such that adding further length to the already counted length did not further change the mean value of nuclei per unit length. As the number of nuclei $\left(\mathrm{N}_{\beta}\right)$ strongly increases with $t_{\text {pull }}$ and $v_{\text {pull }}$, the distance between the nuclei becomes less and as a result the determination of nuclei becomes more difficult. This will increase the absolute error in the number of counted nuclei and limits the range of experimentally accessible values of $t_{\text {pull }}$ and $v_{\text {pull }}$.

The number of $\beta$-nuclei $\left(\mathrm{N}_{\beta}\right)$ was found to increase strongly with increasing $v_{\text {pull }}$, as seen in Figure 13 (note the logarithmic scale). The solid line in the figure is the most probable fit through the data points. Figure 13 gives an indication of a minimum shear rate for $\beta$-nucleus formation for the experimental conditions used (see the dashed line). The $\mathrm{N}_{\beta}$ per length will not reach zero because of the presence of sporadic nucleation of the $\beta$-phase in the crystallization of iPP. The limit is approximated by a line at $v_{\text {pull }} \approx$ $1 \mathrm{~mm} / \mathrm{s}$.

The growth rate of the cylindrites was determined for various samples mentioned in Table 1. Growth rates of the cylindrites were determined by measuring the increase of the diameter perpendicular to the 

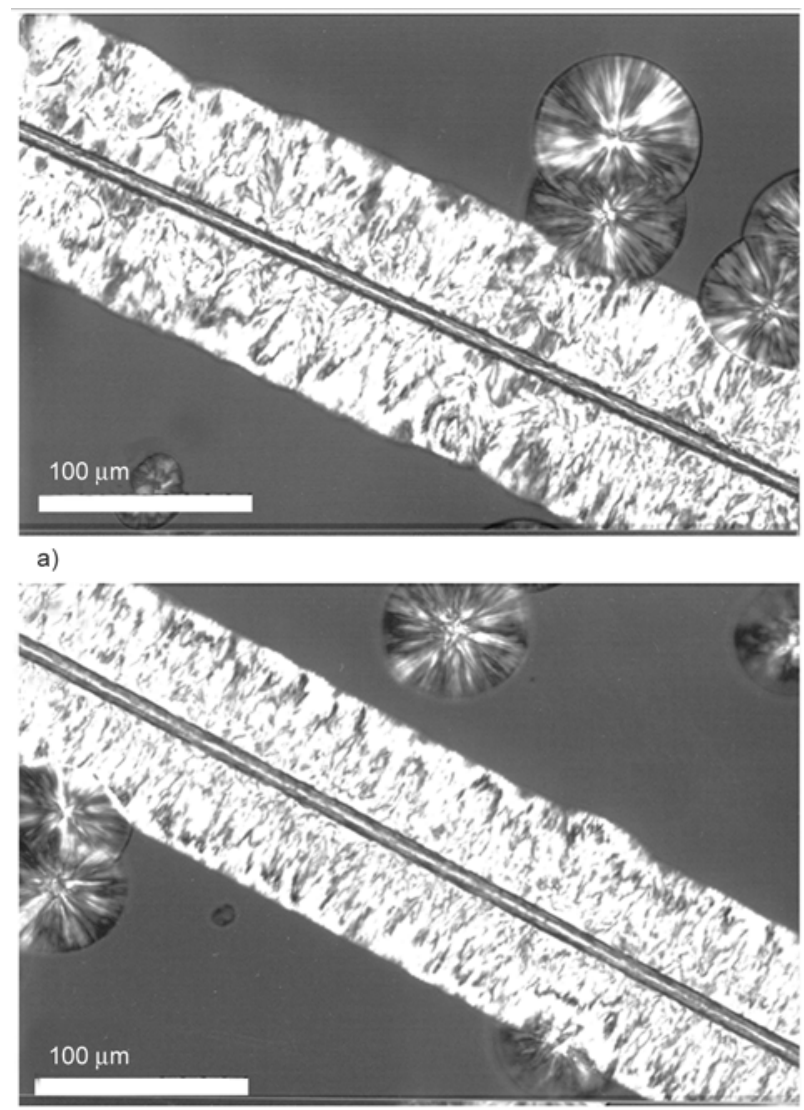

c)

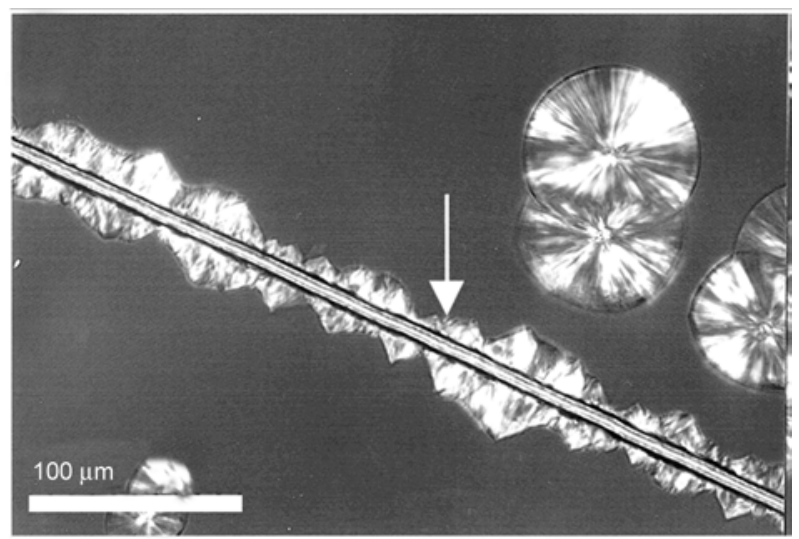

b)

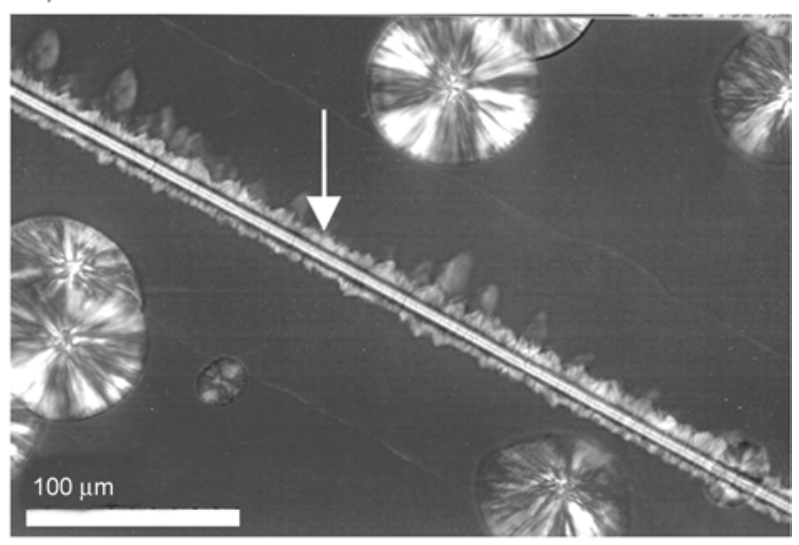

d)

Figure 12. PLM micrographs of cylindritic morphologies formed in typical shear experiments with $t_{\text {pull }}=1 \mathrm{~s}$ (a) and $t_{\text {pull }}=$ $8 \mathrm{~s}$ (c). Micrographs (b) and (d) show the morphology after selective melting of the $\beta$-phase.

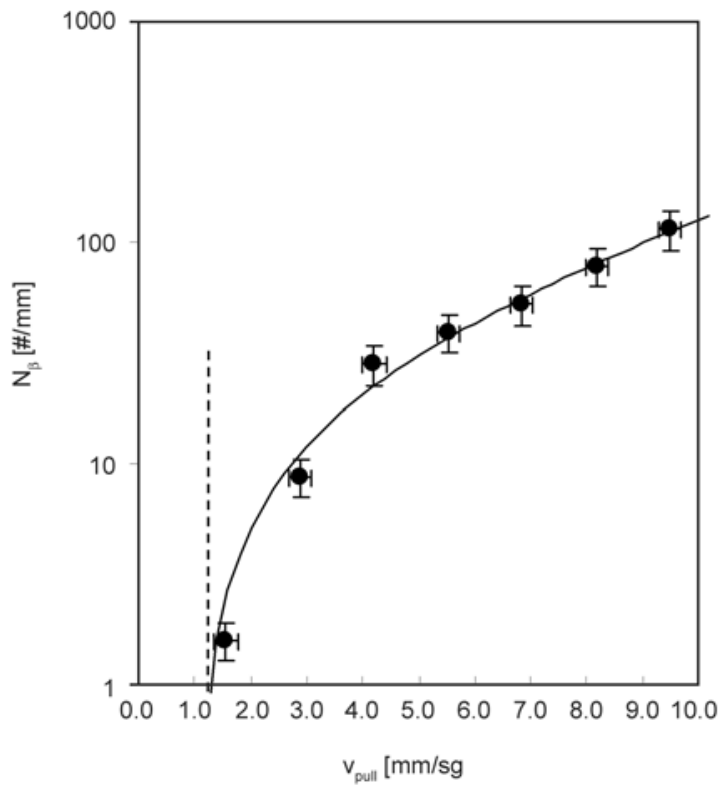

Figure 13. Number of $\beta$-nuclei as function of fibre pull speed $\left(v_{\text {pull }}\right)$

fibre direction as function of time (see the arrows in Figure 11). The size of the cylindrites increased linearly with time and remained linear over the measured time.

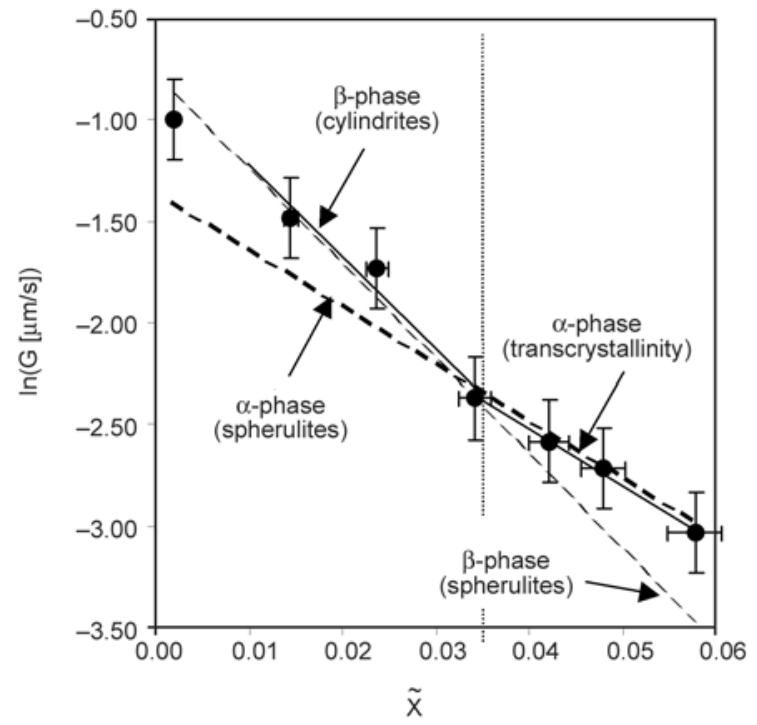

Figure 14. Growth rates of cylindrites after shearing as function of combined defect fraction. Indicated dashed lines are the trend-lines of the growth data from Figure 10 i.e. the growth data measured on spherulites.

Figure 14 shows the growth rates of the cylindritic structures as function of the combined defect fraction $(\widetilde{X})$. In this graph only samples with $\widetilde{X}<0.06$ 
are plotted. The growth rate of the cylindrites is linearly decreasing with increasing $\widetilde{X}$. At $\widetilde{X} \approx 0.03$, a distinct change in the slope can be seen. At this point the growth rates of the $\alpha$-phase equals that of the $\beta$-phase $\left(G_{\alpha}=G_{\beta}\right)$. As the upper crystallization temperature $\left(T_{\beta \alpha}\right)$ is defined by the condition of equal growth rates, we can state the condition $\left(T_{\alpha \beta}<\right.$ $T_{\text {pull }}=T_{\mathrm{c}}<T_{\beta \alpha}$ ) for the formation of $\beta$-cylindrites under shear is no longer fulfilled for samples containing more than $\widetilde{X}<0.03$ defects (for $\widetilde{X}<0.03$, $T_{\beta \alpha}<T_{\mathrm{c}}$ ). From PLM observation we could determine that a $\beta$-cylindritic morphology was formed after shear in the samples with $\widetilde{X}<0.03$. However, samples containing more than $\widetilde{X} \approx 0.03$ defect fraction showed simple $\alpha$-transcrystallisation. The growth rates of the $\beta$ - and $\alpha$-cylindrites were found the same as the growth rates of the $\beta$ - and $\alpha$-spherulites, respectively (see Figure 10). The growth rates of the spherulites ( $\alpha$ - and $\beta$-phase) are indicated as dashed lines in Figure 14. An obvious question arises whether the transition at $\widetilde{X} \approx 0.03$ depends on the speed of the fibre or on the shearing time. We found the transition independent of both parameters, which implies that the condition $T_{\alpha \beta}<T_{\mathrm{c}}<T_{\beta \alpha}$ is a necessary condition to be fulfilled for the formation of the $\beta$-phase under shear.

\section{Discussion}

During the course of crystallization, defects will be partitioned among the amorphous and crystalline phases. It is not possible to establish a priori by theory the actual ratio of the amount of defects incorporated in the two phases, but two extreme cases can be distinguished: complete exclusion and uniform inclusion of defects in the crystal phase [39]. In case of inclusion, the defect can either enter the lattice as an equilibrium requirement, or be located within the lattice as a non-equilibrium defect [39].

Several types of crystal defects can be distinguished [40] such as dislocations, chain disorder, and amorphous defects. Dislocations occur when the periodicity of the crystal is interrupted along a certain direction. Chain disorder is specified as a point defect. It includes chain ends, kinks, and chain torsion. Amorphous defects can be described as an inclusion of a disordered region within the crystal. Obviously, the boundaries between the different types of crystal defects are not sharp and they vary in the energy, which is needed to incorporate such defects into the crystal, i.e. a point like chain disor- der defect may result in an amorphous defect when the chain disorder is high enough. We saw from growth rate measurements that the regio-defects have a more pronounced influence on the crystallization rate as compared to the stereo-defects. In order to obtain a better understanding of the influence of the amount and different types of defects on the growth rate we analysed our data with a theory originally developed by Lauritzen and Hoffman (LH-theory) [41, 42], and later modified by Sanchez and Eby [22, 23]. Although the LH-theory served as the basis for the derivation the theory, the final result will be independent of the exact molecular mechanisms (and thus the molecular background for the theory) involved for the particular case studied.

\subsection{Crystallization of homo-polymers}

In the LH-polymer crystallization theory the spherulitic growth rate $(G)$ at a given undercooling $\Delta T=\left(T_{\mathrm{m}}^{0}-T\right)$ is given by Equation (15):

$$
\begin{aligned}
& G=G_{0} \exp \left(-\frac{U^{*}}{R\left(T-T_{\infty}\right)}\right) \exp \left(-\frac{K_{\mathrm{g}}}{T \cdot \Delta T}\right) \text { or } \\
& \ln G=\ln G_{0}-\frac{U^{*}}{R\left(T-T_{\infty}\right)}-\frac{K_{\mathrm{g}}}{T \cdot \Delta T}
\end{aligned}
$$

where $U^{*}$ is the (material independent) activation energy for polymer diffusion across the phase boundary. For $U^{*}$ the value of $6.28 \mathrm{~kJ} / \mathrm{mol}$ was suggested by Hoffman et al. [42]. $R$ is the universal gas constant; $K_{\mathrm{g}}$ is called the secondary nucleation constant for a given regime; $T_{\infty}$ is the temperature below which diffusion of polymer segments is negligible $\left(T_{\infty}=T_{\mathrm{g}}-30 \mathrm{~K}\right) ; T$ is the crystallization temperature and $T_{\mathrm{m}}^{0}$ is the equilibrium melting temperature for the completely defect-free homopolymer with infinite lamellar thickness and molar mass. The term $G_{0}$ is a pre-exponential factor, which may depend slightly on temperature. However, its contribution to the temperature dependence of $G$ is negligible relative to that of the transport term $\left\{U^{*} /\left[R\left(T-T_{\infty}\right)\right]\right\}$ and the nucleation free energy term $\left\{K_{\mathrm{g}} /(T \cdot \Delta T)\right\}$, respectively [42]. The expression for the secondary nucleation constant is the following Equation (16):

$$
K_{\mathrm{g}}=\frac{n \sigma_{\mathrm{u}} \sigma_{\mathrm{e}} b_{0} T_{\mathrm{m}}^{0}}{R \cdot \Delta H^{0}}
$$

In this equation $\sigma_{\mathrm{u}}$ and $\sigma_{\mathrm{e}}$ are the interfacial lateral free energy and the interfacial surface free energy, respectively. The interfacial free energies defined 
here are related to nucleation (like all other terms) and cannot a priori be identified with characteristics of the mature crystallites that subsequently develop. In Equation (16) the term $b_{0}$ is the layer thickness; $n$ is a coefficient which depends on the growth regime: $n=4$ in regimes I and III and $n=2$ in regime II. For a description of the various regimes we refer to the literature [43]. Inserting Equation (16) into Equation (10) yields the following Equation (17) for the secondary nucleation rate of homo-polymers (regime III) [44]:

$\ln G=\ln G_{0}-\frac{U^{*}}{R\left(T-T_{\infty}\right)}-\frac{4 \sigma_{\mathrm{u}} \sigma_{\mathrm{e}} b_{0} T_{\mathrm{m}}^{0}}{R \Delta H^{0} T \cdot \Delta T}$

As one can see, the growth rate depends exponentially on $T_{\mathrm{m}}^{0} /(T \cdot \Delta T)$, according to Equation (17). The spherulitic growth rate $(G)$ strongly depends on molar mass. At a given temperature, the rate decreases when the molar mass increases up to a value where the growth is not affected by the length of the polymer chain, any further. If the kinetic nucleation theory is used in the infinite molecular mass approximation, the free energy of nucleation is given by Equation (16) and this will be used in further analyses.

\subsection{Crystallization of copolymers}

Crystallization kinetics is influenced by the molar mass and chemical structure of the macromolecules, pressure, strain, and by changes in chain architecture. Modifications of the sequence distribution and tacticity of the polymer chains lead to different crystallization kinetics and thus lead to different properties of the resulting crystallites. As far as crystallization kinetics is concerned, isomerism, stereo irregularities, and branching impart a co-polymeric character to the chain. The theory for copolymer crystallization (and melting) therefore can be applied for regio- and stereo- irregular systems, as well.

Increasing concentration of the chain defects in the polymer chain reduces both the spherulitic growthrate and the overall crystallization rate. Sanchez and Eby [23] derived a general expression for the spherulitic growth rate $G$ (assuming a coherent surface nucleus and regime III growth) (see Equation (18)):

$$
\ln G=\ln G_{0}-\frac{U^{*}}{R\left(T-T_{\infty}\right)}-\frac{2 \sigma_{\mathrm{u}} b_{0} l_{\mathrm{c}, \mathrm{i}}^{0}[1+f(X, T)]}{R T}
$$

It is possible to express the nucleation rate of the copolymer in terms of the homo-polymer nucleation rate plus a term that contains the comonomer concentration if the following function is defined (Equation (19)):

$f(X, T) \equiv \frac{\Delta G^{0}}{\Delta G^{*}}-1$

The term $\Delta G^{0}$ is the bulk free energy difference for the complete defect-free (homo) polymer with infinite lamellar thickness and molar mass compared to the defect containing 'real' lamella of finite thickness and is usually approximated by Equation (20):

$$
\Delta G^{0}=\Delta H^{0}\left(1-\frac{T}{T_{\mathrm{m}}^{0}}\right)
$$

For $\Delta G^{0}$ it is assumed that at moderate undercooling the heat of fusion $\left(\Delta H^{0}\right)$ and entropy of fusion $\left(\Delta S^{0}\right)$ are temperature independent [45]. From the nucleation theory [45] follows Equation (21):

$l_{\mathrm{c}, \mathrm{i}}=\frac{2 \sigma_{\mathrm{e}}}{\Delta G^{0}}+\delta l_{\mathrm{c}}$

where $l_{\mathrm{c}, \mathrm{i}}$ is the initial crystal thickness and $\sigma_{\mathrm{e}}$ is the surface free energy. $\delta l_{\mathrm{c}}$ is the extra thickness a crystal needs to be stable above the crystallization temperature. The minimum crystal thickness at the particular crystallization temperature is given by $2 \sigma_{\mathrm{e}} / \Delta \mathrm{G}^{0}$. Under the assumption that $\delta l_{\mathrm{c}}=0$, we get for crystallized polymers with finite lamellar thicknesses: $l_{\mathrm{c}, \mathrm{i}}^{0}=2 \sigma_{\mathrm{e}} / \Delta G^{0}$. The term $\Delta G^{*}$ is the bulk free energy difference between a crystal with partially included defects with concentration $X_{\mathrm{c}}$ and the melt with a concentration of defects equal to the overall defect composition $X . \Delta G^{*}$ is given by Equation (22) [39]:

$$
\begin{aligned}
& \Delta G^{*}=\Delta G^{0}- \\
& \quad-R T\left(\frac{\varepsilon X_{\mathrm{c}}}{R T}+\left(1-X_{\mathrm{c}}\right) \cdot \ln \frac{1-X_{\mathrm{c}}}{1-X}+X_{\mathrm{c}} \cdot \ln \frac{X_{\mathrm{c}}}{X}\right)
\end{aligned}
$$

The excess free energy of the defect, created by incorporating a defect in the crystalline lattice is labelled by $\varepsilon$.

The tendency to enter the lattice depends on the excess free energy of the defect $(\varepsilon)$. It was shown [39] that under equilibrium conditions the fraction of defects, which enter the crystal lattice with a penalty $\varepsilon$ can be calculated using Equation (23) [46]: 
$X_{\mathrm{c}}^{\mathrm{eq}}=\frac{X \mathrm{e}^{-\varepsilon / \mathrm{RT}}}{(1-X)+X \mathrm{e}^{-\varepsilon / \mathrm{RT}}}$

The parameter $X_{\mathrm{c}}^{\mathrm{eq}}$ is the equilibrium fraction of defects in the crystal and $X$ is the global defect fraction of the melt prior to crystallization. Insertion of Equation (23) into Equation (22) yields the free energy of crystals with an equilibrium defect concentration given by Equation (24) [39]:

$\Delta G^{*}=\Delta G^{0}+R T \cdot \ln \left(1-X+X \mathrm{e}^{-\varepsilon / \mathrm{RT}}\right)$

When the concentration of defects is negligible $\left(X_{\mathrm{c}}=0\right)$ then Equation (22) is reduced to the exclusion limit:

$\Delta G^{*}=\Delta G^{0}+R T \cdot \ln (1-X)$

Equation (25) can also be obtained from Equation (24) by increasing $\varepsilon$ to infinity $(\varepsilon \rightarrow \infty)$. Using the equations for the bulk free energy difference between a crystal with partially included defects and the copolymer melt $\left(\Delta G^{*}\right)$ in conjunction with Equation (19) we obtain Equation (26) for the parameter $f(X, T)$ :

$$
\begin{aligned}
f(X, T) & =\frac{-R T \cdot \ln \left(1-X+X \mathrm{e}^{-\varepsilon / \mathrm{RT}}\right)}{\Delta G^{0}+R T \cdot \ln \left(1-X+X \mathrm{e}^{-\varepsilon / \mathrm{RT}}\right)}= \\
& =\lim _{X \longrightarrow 0} \frac{R T \cdot X}{\Delta G^{0}}\left(1-\mathrm{e}^{-\varepsilon / \mathrm{RT}}\right)
\end{aligned}
$$

and Equation (27)

$f(X, T)=\frac{-R T \cdot \ln (1-X)}{\Delta G^{0}+R T \cdot \ln (1-X)}=\lim _{\mathrm{X} \longrightarrow 0} \frac{R T \cdot X}{\Delta G^{0}}$

for the equilibrium and total exclusion limit, respectively.

Since the expressions for $f(X, T)$ are given for the different cases, we can continue with the general expression for the spherulitic growth rate $G$ (Equation (18)). As $f(X, T)$ incorporates the influence of the defects on the crystallization, it is possible to separate the terms referring to the copolymer and the homopolymer, respectively. Under the assumption that the transport term is independent of the copolymer composition for low defect fractions $(X<0.15)$, the separation of terms results in the Equation (28) for $\ln G$ :

$\ln G=\ln G^{0}-\frac{2 \sigma_{\mathrm{u}} b_{0} l_{\mathrm{c}, \mathrm{i}}^{0} f(X, T)}{R T}$ or $\ln G=\ln G^{0}-\frac{4 \sigma_{\mathrm{u}} \sigma_{\mathrm{e}} b_{0} T_{\mathrm{m}}^{0} f(X, T)}{R T \cdot \Delta H^{0} \cdot \Delta T}$

where $G^{0}$ is the growth rate of the homopolymer (not the preexponential factor $\left.G_{0}\right)$. Inserting the expressions for $f(X, T)$ (i.e. Equation (26) or (27)) into Equation (28) yield the growth rate in case of equilibrium inclusion of defects into the crystal (Equation (29)):

$$
\begin{aligned}
\ln G & =\ln G^{0}- \\
& -\frac{4 \sigma_{\mathrm{u}} \sigma_{\mathrm{e}} b_{0} T_{\mathrm{m}}^{0} \cdot R T \cdot \ln \left(1-X+X \mathrm{e}^{-\varepsilon / \mathrm{RT}}\right)}{R \cdot \Delta H^{0} \cdot T \cdot \Delta T \cdot\left(\Delta G^{0}+R T \cdot \ln \left(1-X+X \mathrm{e}^{-\varepsilon / \mathrm{RT}}\right)\right)}
\end{aligned}
$$

and the growth rate in the case of total exclusion of defect is given by Equation (30):

$$
\ln G=\ln G^{0}-\frac{4 \sigma_{\mathrm{u}} \sigma_{\mathrm{e}} b_{0} T_{\mathrm{m}}^{0} \cdot R T \cdot \ln (1-X)}{R \cdot \Delta H^{0} \cdot T \cdot \Delta T \cdot\left(\Delta G^{0}+R T \cdot \ln (1-X)\right)}
$$

Equation (30) is the same expression for the copolymer crystallization as described by Alamo and Mandelkern [1] and Helfand and Lauritzen [46]. In case $X=0$ Equation (29) and Equation (30) reduce to the homo-polymer case as described above.

\subsection{Analysis of the crystallization behaviour of the $\alpha$ - and $\beta$-phases of iPP}

In this section we analyze the results of the dependence of the growth rates on the fraction of defects with the theory described in the sections above. At the crystallization temperature used in the experiments, iPP crystallizes in regime III [43], which makes it possible to use Equation (29) or (30) given in the previous analysis. In the Equation (29) or (30) the expression for $\Delta G^{0}$ is given by Equation (20) and the remaining parameters can be found in literature $[2,3,47]$. However, the reported values, especially for $\sigma_{\mathrm{u}}$ and $\sigma_{\mathrm{e}}$, widely scatter [13] and limit a useful calculation of $K_{\mathrm{g}}$ and $\Delta G^{0}$. Therefore, the parameters were determined independently using the growth rate expression for the homopolymer, see Equation (17). As a representative for a homopolymer we took the polymer with the least amount of defects (M4).

The growth rate of this polymer as function of temperature was determined. From a plot of 
$\ln G+U^{*} /\left(R\left(T-T_{\infty}\right)\right)$ against $1 /(T \cdot \Delta T)$ we obtain from Equation (17) the following term from the slope (Equation (31)):

$\frac{4 \sigma_{\mathrm{u}} \sigma_{\mathrm{e}} b_{0} T_{\mathrm{m}}^{0}}{R \cdot \Delta H^{0}}=K_{\mathrm{g}}$

which contains all the necessary parameters (including $\sigma_{\mathrm{u}}$ and $\sigma_{\mathrm{e}}$ ) for the calculation of $\ln G$, see Equation (28). The growth rates were measured for temperatures between 396 and 408 K. Figure 15 shows the result. From the slope we obtain the following values for the $\alpha$-phase: $K_{\mathrm{g}}=3.68 \cdot 10^{5} \mathrm{~K}^{2}$ and $\beta$ phase: $K_{\mathrm{g}}=2.46 \cdot 10^{5} \mathrm{~K}^{2}$, respectively.

The only unknown parameter, which is left for the calculation of $\ln G$ as function of $X$ is the excess free energy $(\varepsilon)$ needed to incorporate a stereo defect into a crystal lattice. This parameter is used as a fitting parameter. The fitting of $\ln G$ as function of $X$ using Equation (29) and Equation (30) was performed for the $\alpha$ - as well as for the $\beta$-phase.

Figure 16 shows both the fitted as the measured $\ln G$ as function of $X$, respectively. An excellent agreement is found between the calculated growth rates using the equilibrium inclusion of defects and the observed growth rate data for samples containing only a variation in the amount of stereo-defects (Figure 17). It is found that the growth rates of the defected polymer samples are decreased compared to the homopolymer samples. The model correctly predicts a critical defect fraction for which $G_{\alpha}=G_{\beta}$. In the fitting, we assumed a value of the excess free energy value for including a stereo-defect into an $\alpha$ phase crystal of $\varepsilon=1.6 \mathrm{~kJ} \cdot \mathrm{mol}^{-1}$. The value for the excess energy for including a stereo-defect into the

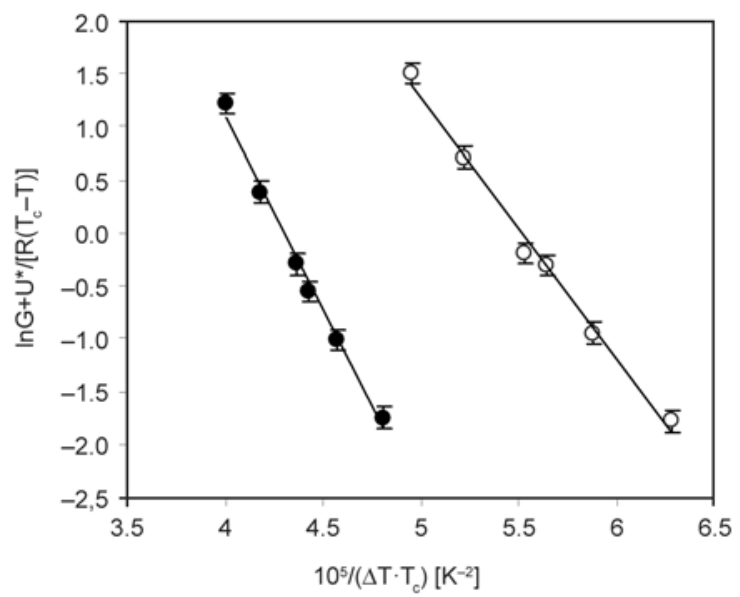

Figure 15. Plot of $\ln G+U^{*} /\left(R\left(T-T_{\infty}\right)\right)$ against $1 /(T \cdot \Delta T)$. Closed symbols $(\bullet)$ represent the $\alpha$-phase, open symbols (०) indicate the $\beta$-phase. $\beta$-phase lattice is $\varepsilon=1.2 \mathrm{~kJ} \cdot \mathrm{mol}^{-1}$. The excess free energy is thus lower for the trigonal crystal as compared to the monoclinic crystal.

For the fitting of the samples with regio-defects we maximized the excess defect free energy $(\varepsilon \rightarrow \infty)$, which means that under equilibrium conditions virtually no regio-defects are included in the crystal (conform with Equation (30). The growth rate data of the samples with a varying amount of regiodefects could be less satisfactorily fitted with the model. The model accounts for the much larger decrease in the growth rate due to the expelling of defects from the lattice. The model also rightly predicts the growth rate of the $\beta$-phase relative to the $\alpha$ phase, i.e. the model shows a lower growth rate for the $\beta$-phase instead of the $\alpha$-phase.

As the total exclusion of defects cannot account for the strong deceleration of the spherulitic growth rate in polymers exhibiting regio-defects, we can conclude that a certain amount of the total fraction of regio-defect will be included into the crystal as non-equilibrium defects, provided that the theory we used can be applied. The fraction of regio-defects incorporated into the crystal phase will be lower as compared to the fraction of stereo-defect, as the excess free energy of regio-defects is much higher.

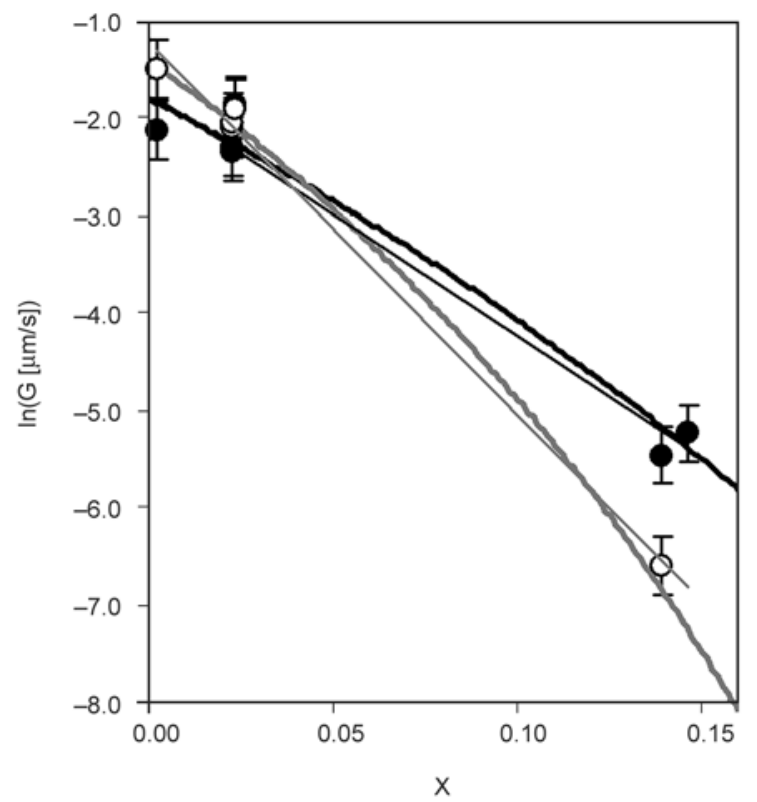

Figure 16. Calculated and measured growth rates of the $\alpha$ and $\beta$-phases in the case of equilibrium inclusion of defects. The thick black-lines ( - ) and thick grey-lines (-) label the results for the $\alpha$ phase and $\beta$-phase, respectively. Indicated are the measured growth rate data (and trend lines) for the stereo-defected samples (group 1); (०)= $\beta$-phase; $(\bullet)=\alpha$-phase. 

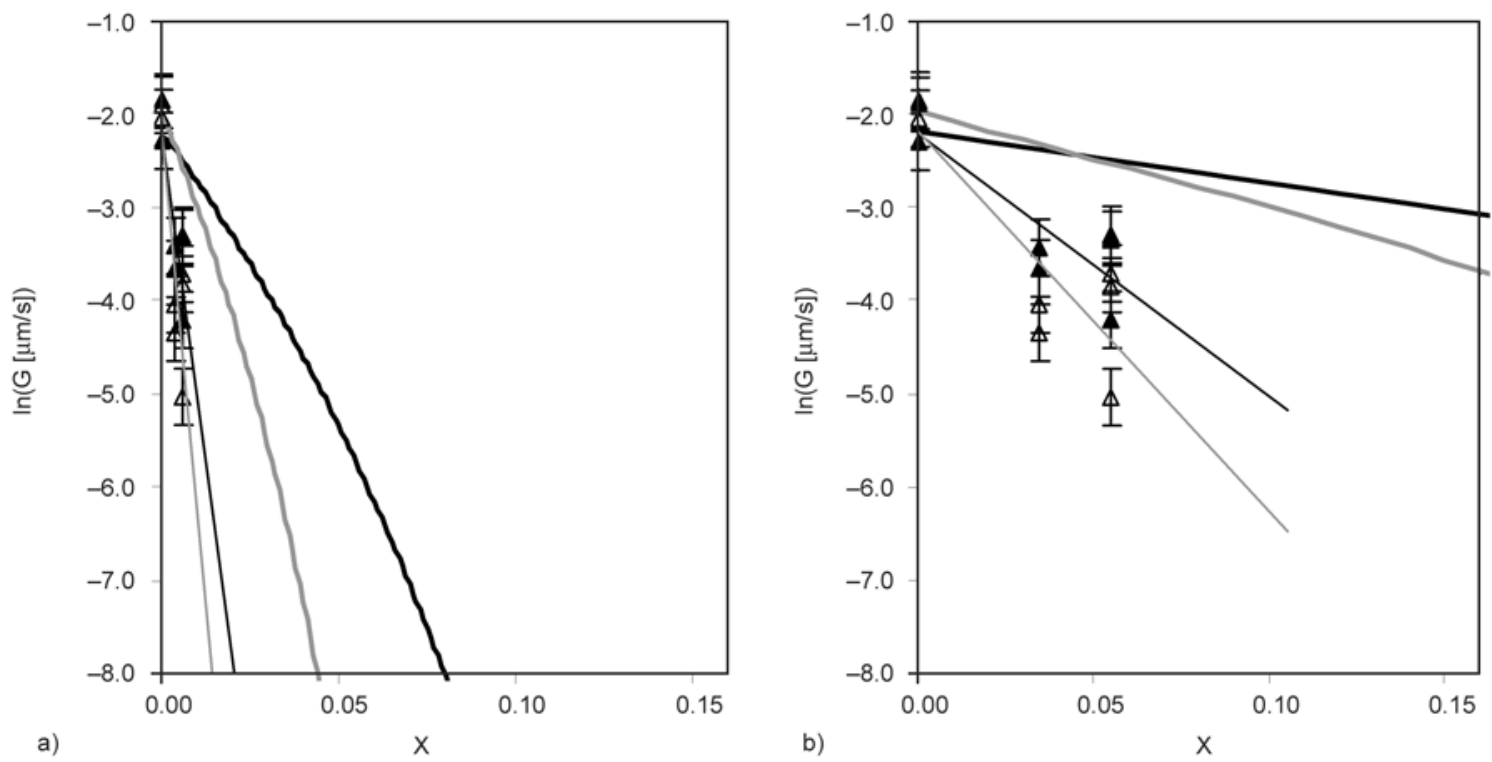

Figure 17. (a) Calculated and measured growth rates of the $\alpha$ - and $\beta$-phases in the case of total exclusion of defects; (b) Magnification of a section showed in (a) for low defect fractions. The thick black-lines ( - ) and thick grey-lines (-) label the results for the $\alpha$-phase and $\beta$-phase, respectively. Indicated are the measured growth rate data (and trend lines) for the regio-defected samples (group 2); $(\mathbf{\Delta})=\beta$-phase; $(\Delta)=\alpha$-phase.

From the analysis developed above we find that the growth rate dependence on $X$ is determined by the product of $K_{\mathrm{g}}$ with $f(X, T)$. From Figure 16 it was concluded that the value of $K_{\mathrm{g}}$ for the $\beta$-phase is smaller as compared to the $\alpha$-phase, which would mean that the growth rate of $\alpha$-phase is stronger influence by the incorporation of defects in the chain as compared to the $\beta$-phase. However, from Figure 10 we saw that the growth rate of the $\beta$-phase is a stronger function of $X$. As a consequence we may conclude that $f(X, T)$ predominantly determines the growth rate dependence on $X$ compared with the effect of $K_{\mathrm{g}}$. To visualize this influence, the parameter $f(X, T)$ was calculated separately for both total exclusion of defects and uniform inclusion (for the $\alpha$ - as well as for $\beta$-phases). The results of the calculations of $f(X, T)$ are graphically presented in Figure 18.

As expected, $f(X, T)$ increases with increasing defect fraction. Figure 18 shows that for small $X$ the parameter $f(X, T)$ is approximately a linear function of the fraction of defects. However, $f(X, T)$ diverts from linearity for larger defect fraction. Obviously this has consequences for the prediction of the growth rate depression (see Figure 17). In the original derivation for $f(X, T)$ by Sanchez and Eby [23], the expressions for $f(X, T)$ were expanded in a power series under the assumption of small $X(X<0.1)$. Although mathematically correct, the expansion in power series is not required and in this paper use was made of the

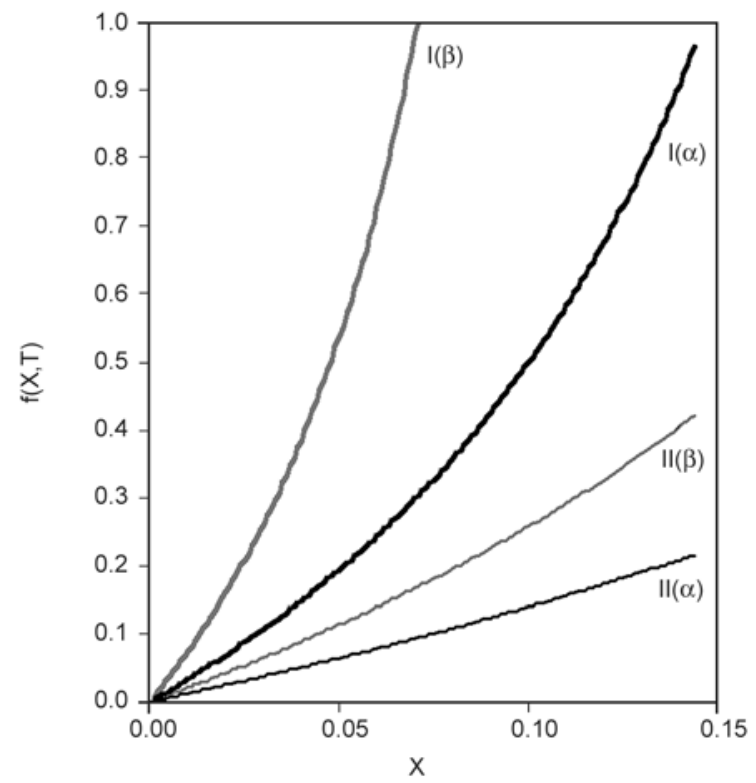

Figure 18. The parameter $f(X, T)$ as function of $X$ for the $\alpha$ and $\beta$-phases, respectively. I) $f(X, T)$ in case of total exclusion (Equation (27)), II) $f(X, T)$ in the case of equilibrium inclusion (Equation (26)).

basic expressions of $f(X, T)$ for copolymers. The trend of $f(X, T)$ with $X$ (especially for small $X$ ) is very sensitive on the value of the bulk free energy of the homo-polymer $\left(\Delta G^{0}\right)$, see Equations (26) and (27). It also follows from the theory that the excess free energy of the homopolymer largely determines the magnitude of the growth rate dependence on $X$. The higher the value of $\varepsilon$ the larger the dependence of the 
growth rate on the number of defects. The influence of $X$ on the growth rate is maximum when the energy of inclusion is infinite. A higher value of $\varepsilon$ would result in a lower content of defects in the lattice. Under non-equilibrium conditions some of the defects will be introduced into the lattice. Energetically the inclusion of such defects is very unfavourable and therefore will retard, or even cease, the crystallization at that point. In principle, the distribution of defects between the amorphous and crystalline regions might depend on both the crystallization kinetics and on the crystal characteristics. It is not possible to establish a priori by theory the actual ratio of the amount of defects among the two phases [39]. Alamo et al. [48, 49] made large progress in determining the partitioning of several types of defects experimentally for stereo- and regio-defects of iPP ( $\alpha$-phase) using ${ }^{13} \mathrm{C}$-NMR. They demonstrated that the partitioning of the defects does not depend on the kinetics of crystallization, which implies that the partitioning is 'predetermined' for a certain polymer chain. Whether this is the case for our systems needs further investigation.

In the section Results we defined the following function (Equation (9) and (10)) for the growth rate of the $\alpha$-phase (Equation (32) and (33)):

$\ln G_{\alpha, S / r}=-(2.5 \pm 0.2) \cdot 10^{1} \widetilde{X}-(1.74 \pm 0.22)$

where $\widetilde{X}=X_{\mathrm{s}}+(11.1 \pm 3.1) X_{\mathrm{r}}$

A combined defect fraction $(\widetilde{X})$ was introduced and defined as the sum of the number of stereo-defects and the number of regio-defects multiplied by a given regio-error coefficient with a certain value $\mathrm{t}(11.1 \pm 3.1)$. With the current copolymer crystallization theory an expression for the regio-error coefficient can be found. Similarly as done earlier we construct a linear combination of the expression describing the (theoretically found) growth rates of samples containing stereo- and regio-defects (Equation (34):

$$
\begin{aligned}
\ln G_{\alpha, \mathrm{s} / \mathrm{r}}= & -\frac{2 \sigma_{\mathrm{u}} \sigma_{\mathrm{e}} b_{0}}{R \cdot \Delta H^{0} \cdot T \cdot \Delta T} f\left(X_{\mathrm{r}}, T\right)- \\
& -\frac{2 \sigma_{\mathrm{u}} \sigma_{\mathrm{e}} b_{0}}{R \cdot \Delta H^{0} \cdot T \cdot \Delta T} f\left(X_{\mathrm{s}}, T\right)-\ln G^{0}
\end{aligned}
$$

We can introduce Equation (35):
$f\left(X_{\mathrm{r}}, T\right) \equiv f^{\prime}\left(X_{\mathrm{r}}, T\right) \cdot X_{\mathrm{r}}$ and $f\left(X_{\mathrm{s}}, T\right) \equiv f^{\prime}\left(X_{\mathrm{s}}, T\right) \cdot X_{\mathrm{S}}$

By inserting Equation (35) in Equation (34) the following result can be obtained:

$\ln G_{\alpha, S / \mathrm{r}}=-\left(\frac{2 \sigma_{\mathrm{u}} \sigma_{\mathrm{e}} b_{0}}{R \cdot \Delta H^{0} \cdot T \cdot \Delta T} f^{\prime}\left(X_{\mathrm{s}}, T\right)\right) \cdot \widetilde{X}$

with $\widetilde{X}=X_{s}+\frac{f^{\prime}\left(X_{\mathrm{r}}, T\right)}{f^{\prime}\left(X_{\mathrm{s}}, T\right)} \cdot X_{\mathrm{r}}$

Equations (36) and (37) are mathematically similar to Equations (9) and (10) or (32) and (33) when $f^{\prime}\left(X_{\mathrm{s}}, T\right)$ is not a strong function of $X$ and thus can be approximated by a constant. In principle this is only valid for small $X_{\mathrm{s}}$. However, since $f\left(X_{\mathrm{s}}, T\right)$ is approximately a linear function of $X_{\mathrm{s}}$ (as was for example shown in Figure 18 by the curves II $\alpha$ and II $\beta$ ) we may assume that $f^{\prime}\left(X_{\mathrm{s}}, T\right)$ is approximately constant for larger $X_{\mathrm{s}}$, as well. Equation (36) and (37) give an expression for the combined defect fraction and regio-error coefficient. The regio-error coefficient is given by: $f^{\prime}\left(X_{\mathrm{r}}, T\right) / f^{\prime}\left(X_{\mathrm{s}}, T\right)$. A similar analysis can be done for the $\beta$-phase and will yield a similar result. Equation (36) and (37) provides us with the opportunity to describe any sample exhibiting both stereo- and regio-defects.

\section{Conclusions}

For the research described in this paper we collected an unprecedented group of polypropylene polymers with a wide variety of stereo- and regiodefects. The characteristics of the samples were such that we could independently investigate the influence of the type of defect on the crystallization rates of the $\alpha-, \beta-$, and $\gamma$-phases, respectively.

Growth rates of the $\alpha$-, and $\beta$-polymorphs were measured under isothermal crystallization conditions as a function of the amount and type of defects. The growth rate dependence of the $\beta$-phase on the number of defects was much larger as compared with the $\alpha / \gamma$-phases. As the growth rate of the $\beta$ phase is higher for pure iPP, but lower for more defected iPPs, a critical defect fraction was found for which the growth rates of both phases are the same. For samples having this specific critical defect fraction the upper critical crystallization temperature of iPP is lowered to $130^{\circ} \mathrm{C}$. 
A combined defect fraction (CDF) was introduced to uniformly and uniquely describe all samples with a random arbitrary amount and type of defects. The $\mathrm{CDF}$ is the sum of the number of stereo-defects and the number of regio-defects multiplied by a certain regio error coefficient. This coefficient showed that the influence on crystallization of regio-defects compared with stereo-defects is much larger.

Crystallization rates were analyzed according to the theory of Sanchez and Eby. The theory rightly predicts the stronger dependence of the growth rate of the $\beta$-phase on the defect fraction as compared with $\alpha$-phase. The theory also predicts the critical defect fraction for which the growth rates of the $\alpha$ - and $\beta$ phases are equal. The equilibrium conditions for which the theory initially has been developed provides the boundaries for the non-equilibrium crystallization of copolymers. Finally, the theory gives an analytically expression for the CDF and the corresponding weighting factor.

In conclusion, we may state that iPP is a polymorphic polymer that provides us with a unique opportunity to study the influence of the chain architecture (regio-defects independently of stereo-defects) on the crystallization and thus on the three crystallinephases existing in iPP.

\section{Acknowledgements}

The authors thank Dr. A. Demain (Fina Research, Feloy, Belgium), Dr. I. Mingozzi (Basell, Ferrara, Italy), Dr. J. Chadwick and Dr. F. van der Burght (Technical University of Eindhoven, The Netherlands) for the polymer samples. The authors also greatly acknowledge Dr. S. Rastogi (Technical University of Eindhoven, Eindhoven, The Netherlands) for providing the opportunity to perform the SAXS and WAXS measurements and Dr. G. van den Velde for the NMR-measurements and useful discussions. This research was financially supported by the Dutch Polymer Institute and the MESA+ Institute for Nanotechnology of the University of Twente.

\section{References}

[1] Alamo R. G., Mandelkern L.: Crystallization kinetics of random ethylene copolymers. Macromolecules, 24, 6480-6493 (1991). DOI: $10.1021 / \mathrm{ma} 00024 \mathrm{a} 018$

[2] Cheng S. Z. D., Janimak J. J., Zhang A., Zhang A., Hsieh E. T.: Isotacticity effect on crystallization and melting in polypropylene fractions: 1 . Crystalline structures and thermodynamic property changes. Polymer, 32, 648-655 (1991).

DOI: $\underline{10.1016 / 0032-3861(91) 90477-Z}$
[3] Janimak J. J., Cheng S. Z. D., Giusti P. A., Hsieh E. T.: Isotacticity effect on crystallization and melting in polypropylene fractions. II. Linear crystal growth rate and morphology study. Macromolecules, 24, 2253-2260 (1991).

DOI: $10.1021 / \mathrm{ma} 00009 \mathrm{a} 020$

[4] Fischer D., Mülhaupt R.: The influence of regio- and stereoirregularities on the crystallization behaviour of isotactic poly(propylene)s prepared with homogeneous group IVa metallocene/methylaluminoxane ZieglerNatta catalysts. Macromolecular Chemistry and Physics, 195, 1433-1441 (1994).

DOI: $10.1002 /$ macp.1994.021950426

[5] De Rosa C., Auriemma F., Paolillo M., Resconi L., Camurati I: Crystallization behavior and mechanical properties of regiodefective, highly stereoregular isotactic polypropylene: Effect of regiodefects versus stereodefects and influence of the molecular mass. Macromolecules, 38, 9143-9154 (2005).

DOI: $10.1021 / \mathrm{ma} 051004 \mathrm{x}$

[6] Suhm J., Heinemann J., Thomann Y., Thomann R., Maier R-D., Schleis T., Okuda J., Kressler J., Mülhaupt R.: New molecular and supermolecular polymer architectures via transition metal catalysed alkene polymerization. Journal of Materials Chemistry, 8, 553-563 (1998). DOI: 10.1039/A706451I

[7] Thomann R., Wang C., Kressler J., Mülhaupt R.: On the $\gamma$-phase of isotactic polypropylene. Macromolecules, 29, 8425-8434 (1996).

DOI: $10.1021 / \mathrm{ma951885 \textrm {f }}$

[8] Thomann R., Semke H., Maier R-D., Thomann Y., Scherble J., Mülhaupt R., Kressler J.: Influence of stereoirregularities on the formation of the $\gamma$-phase in isotactic polypropene. Polymer, 42, 4597-4603 (2001). DOI: $10.1016 / \mathrm{S} 0032-3861(00) 00675-3$

[9] Radhakrishnan J., Ichikawa K., Yamada K., Toda A., Hikosaka M.: Nearly pure $\alpha 2$ form crystals obtained by melt crystallization of high tacticity isotactic polypropylene. Polymer, 39, 2995-2997 (1998).

DOI: 10.1016/S0032-3861(97)00617-4

[10] Karger-Kocsis J., Varga J., Ehrenstein G. W.: Comparison of the fracture and failure behavior of injectionmolded $\alpha$ - and $\beta$-polypropylene in high-speed threepoint bending tests. Journal of Applied Polymer Science, 64, 2057-2066 (1997).

DOI: 10.1002/(SICI)1097-4628(19970613)64:11<2057 $\because$ AID-APP1>3.0.CO;2-I

[11] Varga J.: $\beta$-modification of isotactic polypropylene: Preparation, structure, processing, properties, and application. Journal of Macromolecular Science Part B: Physics, 41, 1121-1171 (2002).

DOI: $10.1081 / \mathrm{MB}-120013089$

[12] Varga J., Schulek-Tóth F.: Crystallization, melting and spherulitic structure of $\beta$-nucleated random propylene copolymers. Journal of Thermal Analysis, 47, 941-955 (1996).

DOI: $10.1007 / \mathrm{BF} 01979441$ 
[13] Varga J.: Crystallization, melting and supermolecular structure of isotactic polypropylene. in 'Polypropylene: Structure, blends and composites' (ed.: Karger-Kocsis J.) Chapman and Hall, London, Vol 1, 56-115 (1995).

[14] Devaux E., Chabert B.: Nature and origin of the transcrystalline interphase of polypropylene glass fibre composites after a shear stress. Polymer Communications, 32 464-468 (1991).

[15] Varga J., Karger-Kocsis J.: Direct evidence of rownucleated cylindritic crystallization in glass fiber-reinforced polypropylene composites. Polymer Bulletin, 30, 105-110 (1993).

DOI: $10.1007 / \mathrm{BF} 00296241$

[16] Thomason J. L., van Rooyen A. A.: Transcrystallized interphase in thermoplastic composites. Journal of Materials Science, 27, 897-907 (1992). DOI: $10.1007 / \mathrm{BF} 01197639$

[17] Alfonso G. C., Scardigli P.: Melt memory effects in polymer crystallization. Macromolecular Symposia, 118, 323-328 (1997).

DOI: $10.1002 /$ masy. 19971180143

[18] Tribout C., Monasse B., Haudin J. M.: Experimental study of shear-induced crystallization of an impact polypropylene copolymer. Colloid and Polymer Science, 274, 197-208 (1996).

DOI: $10.1007 / \mathrm{BF} 00665636$

[19] Varga J., Karger-Kocsis J.: Rules of supermolecular structure formation in sheared isotactic polypropylene melts. Journal of Polymer Science Part B: Polymer Physics, 34, 657-670 (1996).

DOI: 10.1002/(SICI)1099-0488(199603)34:4<657:: AID-POLB6>3.0.CO;2-N

[20] Karger-Kocsis J., Varga J., Drummer D.: Instrumented falling weight impact of coinjection-molded multipolypropylene sandwich plaques containing $\beta$-phase polypropylene core. Journal of Macromolecular Science Part B, 41, 881-889 (2002).

DOI: $10.1081 / \mathrm{MB}-120013071$

[21] Paukkeri R., Väänänen T., Lehtinen A.: Microstructural analysis of polypropylenes produced with heterogeneous Ziegler-Natta catalysts. Polymer, 34, 24882494 (1993).

DOI: 10.1016/0032-3861(93)90577-W

[22] Sanchez I. C., Eby R. K.: Crystallization of random copolymers. Journal of Research of the National Bureau of Standards A: Physics and Chemistry, 77, 353-358 (1973).

DOI: $10.6028 /$ jres.077A.023

[23] Sanchez I. C., Eby R. K.: Thermodynamics and crystallization of random copolymers. Macromolecules, 8 , 638-641 (1975).

DOI: $10.1021 / \mathrm{ma} 60047 \mathrm{a} 012$

[24] Randall J. C.: Carbon-13 nuclear magnetic resonance quantitative measurements of average sequence lengths of like stereochemical additions in polypropylene and polystyrene. Journal of Polymer Science: Polymer Physics Edition, 14, 2083-2094 (1976).

DOI: $10.1002 /$ pol.1976.180141113
[25] Resconi L., Balboni D.. Baruzzi G., Fiori C., Guidotti S., Mercandelli P., Sironi A.: rac-[methylene(3-tertbutyl-1-indenyl) ${ }_{2} \mathrm{ZrCl}_{2}$ : A simple, high-performance zirconocene catalyst for isotactic polypropene. Organometallics, 19, 420-429 (2000).

DOI: $10.1021 / 0 m 990487$ o

[26] Busico V., Cipullo R., Monaco G., Vacatello M., Segre A. L.: Full assignment of the ${ }^{13} \mathrm{C}$ NMR spectra of regioregular polypropylenes: Methyl and methylene region. Macromolecules, 30, 6251-6263 (1997). DOI: $10.1021 / \mathrm{ma} 970466 \mathrm{a}$

[27] Turner-Jones A., Aizlewood J. M., Beckett D. R.: Crystalline forms of isotactic polypropylene. Die Makromolekulare Chemie, 75, 134-158 (1964).

DOI: $10.1002 / \mathrm{macp} .1964 .020750113$

[28] Hauser G., Schmidtke J., Strobl G.: The role of counits in polymer crystallization and melting: New insights from studies on syndiotactic poly(propene-cooctene). Macromolecules, 31, 6250-6258 (1998). DOI: $10.1021 / \mathrm{ma} 980453 \mathrm{c}$

[29] Varga J., Mudra I., Ehrenstein G. W.: Highly active thermally stable $\beta$-nucleating agents for isotactic polypropylene. Journal of Applied Polymer Science, 74, 2357-2368 (1999).

DOI: 10.1002/(SICI)1097-4628(19991205)74:10<2357 $\because$ AID-APP3 $>3.0 . \mathrm{CO} ; 2-2$

[30] Busico V., Cipullo R.: Microstructure of polypropylene. Progress in Polymer Science, 26, 443-533 (2001). DOI: 10.1016/S0079-6700(00)00046-0

[31] Krache R., Benavente R., López-Majada J. M., Pereña J. M., Cerrada M. L., Pérez E.: Competition between $\alpha, \beta$, and $\gamma$ polymorphs in a $\beta$-nucleated metallocenic isotactic polypropylene. Macromolecules, 40, 68716878 (2007).

DOI: $10.1021 / \mathrm{ma} 0710636$

[32] Alamo R. G., Kim M-H., Galante M. J., Isasi J. R., Mandelkern L.: Structural and kinetic factors governing the formation of the $\gamma$ polymorph of isotactic polypropylene. Macromolecules, 32, 4050-4064 (1999). DOI: $10.1021 / \mathrm{ma} 981849 \mathrm{r}$

[33] Obadal M., Čermák R., Stoklasa K.: Tailoring of threephase crystalline systems in isotactic poly(propylene). Macromolecular Rapid Communications, 26, 12531257 (2005). DOI: $10.1002 /$ marc. 200500272

[34] Varga J., Garzó G., Ille A.: Kristallisation, umkristallisation und schmelzen der $\beta$-modifikation des polypropylens. Die Angewandte Makromolekulare Chemie, 142, 171-181 (1986).

DOI: 10.1002/apmc.1986.051420115

[35] Varga J.: Supermolecular structure of isotactic polypropylene. Journal of Materials Science, 27, 25572579 (1992).

DOI: $10.1007 / \mathrm{BF} 00540671$

[36] Mathieu C., Thierry A., Wittmann J. C., Lotz B.: 'Multiple' nucleation of the (010) contact face of isotactic polypropylene, $\alpha$ phase. Polymer, 41, $7241-7253$ (2000). DOI: $10.1016 / \mathrm{S} 0032-3861(00) 00062-8$ 
[37] Wu C-M., Chen M., Karger-Kocsis J.: The role of metastability in the micromorphologic features of sheared isotactic polypropylene melts. Polymer, 40, 4195-4203 (1999). DOI: 10.1016/S0032-3861(98)00682-X

[38] Vancso G. J., Liu G., Karger-Kocsis J., Varga J.: AFM imaging of interfacial morphologies in carbon-fiber reinforced isotactic polypropylene. Colloid and Polymer Science, 275, 181-186 (1997).

DOI: $10.1007 / \mathrm{s} 003960050069$

[39] Mandelkern L.: Crystallization and melting. in 'Comprehensive polymer science' (eds.: Booth C., Price C.) Pergamon Press, Oxford, Vol 2, 363-414 (1989).

[40] Wunderlich B.: Macromolecular physics. Academic Press, New York (1973).

[41] Lauritzen J. I., Hoffman J. D.: Extension of theory of growth of chain-folded polymer crystals to large undercoolings. Journal of Applied Physics, 44, 4340-4352 (1973).

DOI: $10.1063 / 1.1661962$

[42] Hoffman J. D., Davis G. T., Lauritzen J. L.: The rate of crystallization of linear polymers. in 'Treatise on Solid State Chemistry' (ed.: Hannay N. B.) Plenum Press, New York, Vol. 3, 497-614 (1976).

[43] Clark E. J., Hoffman J. D.: Regime III crystallization in polypropylene. Macromolecules, 17, 878-885 (1984). DOI: $10.1021 / \mathrm{ma} 00134 \mathrm{a} 058$
[44] Hoffman J. D.: Regime III crystallization in melt-crystallized polymers: The variable cluster model of chain folding. Polymer, 24, 3-26 (1997).

DOI: $10.1016 / 0032-3861(83) 90074-5$

[45] Flory P. J.: Principles of polymer chemistry. Cornell University Press, Ithaca (1953).

[46] Helfand E., Lauritzen J. I.: Theory of copolymer crystallization. Macromolecules, 6, 631-638 (1973). DOI: $10.1021 / \mathrm{ma} 60034 \mathrm{a} 031$

[47] Xu J., Srinivas S., Marand H., Agarwal P.: Equilibrium melting temperature and undercooling dependence of the spherulitic growth rate of isotactic polypropylene. Macromolecules, 31, 8230-8242 (1998). DOI: $10.1021 / \mathrm{ma} 980748 \mathrm{q}$

[48] VanderHart D. L., Alamo R. G., Nyden M. R., Kim MH., Mandelkern L.: Observation of resonances associated with stereo and regio defects in the crystalline regions of isotactic polypropylene: Toward a determination of morphological partitioning. Macromolecules, 33, 6078-6093 (2000). DOI: $10.1021 / \mathrm{ma992041p}$

[49] Alamo R. G., VanderHart D. L., Nyden M. R., Mandelkern L.: Morphological partitioning of ethylene defects in random propylene-ethylene copolymers. Macromolecules, 33, 6094-6105 (2000).

DOI: $\underline{10.1021 / \mathrm{ma} 000267 \mathrm{i}}$ 